\title{
Japanese Encephalitis Virus Generated Neurovirulence, Antigenicity, and Host Immune Responses
}

\author{
Ravi Kant Upadhyay \\ Department of Zoology, D D U Gorakhpur University, Gorakhpur 273009, India \\ Correspondence should be addressed to Ravi Kant Upadhyay; rkupadhya@yahoo.com
}

Received 14 May 2013; Accepted 6 June 2013

Academic Editors: M. Magnani and C. Torti

Copyright ( 2013 Ravi Kant Upadhyay. This is an open access article distributed under the Creative Commons Attribution License, which permits unrestricted use, distribution, and reproduction in any medium, provided the original work is properly cited.

\begin{abstract}
In response to a JE virus attack, infected body cells start secretion of different cytokines and activate innate immune response. Virus starts neuronal invasion by entering into nerve cells and inflecting the central nervous system. It avoids exposure of body's natural immunity and generates neurotrophic effects. Virus causes acute susceptibility to CNS and establishes encephalitis syndrome that results in very high fatality in children. In survivors, JEV inhibits the growth and proliferation of NCPs and imposes permanent neuronal disorders like cognitive, motor, and behavioral impairments. However, body cells start TCR mediated interactions, to recognize viral antigens with class I MHC complex on specific target cells, and operate mass killing of virus infected cells by increased CTL activity. Thus, both cell mediated and antibody interactions plays a central role in protection against JEV. In the present review article virus generated neurovirulence, antigenicity, and host immune responses are described in detail. More emphasis is given on diagnosis, clinical care, and active immunization with well-designed potential antiflavivirus vaccines. Further, for achieving an elite success against JEV, global eradication strategies are to be needed for making vaccination program more responsible and effective in endemic areas.
\end{abstract}

\section{Introduction}

1.1. Japanese Encephalitis Virus. Japanese encephalitis virus (JEV) is an enveloped positive single stranded RNA virus that belongs to genus Flavivirus in the family Flaviviridae. JE is one of the most important endemic diseases that exists in Eastern Asia and Southeastern Asia including India, Nepal, Japan, China, Korea, Thailand, Indonesia, Malaysia, Vietnam, Taiwan, and the Philippines. Recently disease has shown its presence in Continental Australia and New Zealand. JE is a major public health problem, which causes high morbidity and mortality in pediatric groups. It is caused by a dreadful mosquito-borne virus (arbovirus) which is transmitted to human by mosquito, that is, Culex tritaeniorhynchus and Culex vishnui throughout rural areas of Asia. The natural cycle of Japanese encephalitis (JE) virus in endemic areas involves presence of water birds and Culex mosquitoes, particularly Culex tritaeniorhynchus, with pigs being also involved as an amplifying host and providing a link to humans through their proximity to housing. These play important role in amplification, dispersal, and epidemiology of JEV [1]. Transmission of JEV is seasonal, which increases with the increase in number of culicine mosquitoes after more frequent mass breeding in rice paddies in rainy season. It is supported by favorable climatic conditions such as rise in temperature, high humidity, and filling of water reservoirs mainly paddy growing agriculture fields/areas with rainwater. It is the main reason that most of the incidences of JE belong to rural area, hence, the disease is considered primarily a rural problem. In such areas, more than $70 \%$ of all adults have been infected at some point with the arbovirus. JEV is a reemerging virus that causes an estimated 50,000 cases annually, of which 15,000 die and up to $50 \%$ of survivors are left with severe residual neurological complications around the world every year $[2,3]$.

1.2. Flavivirus Genome and Neurovirulence. JEV contains positive single stranded RNA genome, approximately $11 \mathrm{~kb}$ in length. Virus genome contains a single open reading frame with a well-arranged gene order as $5^{\prime}$ C-prM-E-NS1-NS2ANS2B-NS3-NS4A-2K-NS4B-NS5 $3^{\prime}[3,4]$. It encodes viral 
proteins $[5,6]$ mainly a precursor poly protein having three structural proteins (C, prM, and E) and seven nonstructural proteins (NSI, NS2, NS2B, NS3, NS4A, NS4B, and NS5) [7]. Among nonstructural proteins, NS3 is a multifunctional protein having 619 amino acid residues and shows enzymatic activities like serine protease, helicase, and nucleoside triphosphatase. NS3 plays important role in the processing of the viral precursor poly protein and the replication of viral genomic RNA [8]. In infected cells, NS3 is associated with microtubules and tumor susceptibility gene 101 protein and plays essential role in viral packing, intracellular trafficking of various viral components. It was detected in the brain of JEV infected patient mainly in the cytoplasm of pyramidal neurons of the cerebrum [9], granule cells, small cells, and Purkinje cells of the cerebellum $12 \mathrm{~h}$ after-infection. The Purkinje cell of the cerebellum is one of the target cells of JEV infection [9]. NS3 is an important agent that generates neurovirulence in patients [8].

There is another nonspecific protein that is NS1 which is a cell surface protein (soluble entity) that generates neurovirulence in host neural cells after peripheral inoculation of virus. It is a multifunctional protein that assists the virus in neuronal invasion [10] and plays important role in pathogenesis and cellular profusion and acts as a virulence determinant [11-13]. It shows host immune response and also elicits protective immunity in mice [14]; that is why it is used to generate protective antibodies against flavivirus [1517]. It shows homology with dengue virus protein and its deformation affects CNS in mouse [18, 19].

There is another major envelope protein E, which plays important role in viral attachment, membrane fusion, and entry of virus into host cell. It is a major structural protein that contains numerous neutralization epitopes, which mediate attachment of virus to the host cells. E protein also contains one putative N linked glycoylation site at NS154 [20, 21] or a putative receptor-binding domain that induces the host immune response $[22,23]$. Similar to NS1 viral proteins, E proteins are well-known target of the protective antibody response against flavivirus infection and contain virulence determinants [11-17].

In addition, two more structural proteins $\mathrm{C}$ and prM are also identified in JE virus by using cDNA analysis. These contain glycosylation sites that showed protective potential. Moreover, in JE viruses, the prM protein contains one putative N-linked glycosylation site at N15E protein and another site at N154. It shows similarity with TBEV and WNV $\mathrm{N}$ linked glycosylation site in prM or E protein. If a deletion occurs in the above site, it leads to a decrease in viral release [24-26]. Similarly mutations in Pv and HRV2 (Human rhinovirus type 2) envelope and coat protein work as real elements which determine neurovirulence in mice. It was proved by preparation and use of chimeric viruses. Similarly, poliovirus infection is largely confined to a specific subpopulation of neuronal cells that occur in human central nervous system and shows PV tropism and neurovirulence [27]. However, mutations generated in putative N-linked glycosylation sites in Japanese encephalitis virus premembrane (prM) and envelope protein (E) have shown enhanced protective potential [28]. It is well confirmed that prM or $\mathrm{E}$ glycosylation mutants enhance the immune response in mice. Further, N linked glycans of viral proteins play important role in modulating immune response in host cells. These are also important for maintaining appropriate antigenic conformations, mainly neutralization epitopes that potentially alter the proteolytic susceptibility of proteins $[29,30]$.

Though so many biological markers of neurovirulence have been identified which enhance neurovirulence [31] but molecular determinants of virus specific factors which account for virulence are still unknown. These might be highly specific, more confirmatory than biological markers because they encoded within multiple regions of neurotropic RNA viruses [32-34]. Mutations occurring in structural and nonstructural viral proteins are responsible for generation of neurovirulence. These might be of reversion or deletion type. It is also proved by single site mutations generated in the flavivirus genome, which encode envelope protein hinge region that resulted in a significant increase in virulence in mice and monkeys [35]. However, mutations occurred in matrix (M) protein of vesicular stomatitis virus (VSV) generate neurovirulence. These $\mathrm{M}$ protein mutants of VSV can be used as vaccine vectors [36]. Contrary to this measles virus also shows very high neuroinvasivness in animal models but shows limiting neurovirulence in humans. Similarly, poliovirus causes very high susceptibility to CNS and grows in neural cells but shows a limited neurovirulence in host [27]. Further serial passages in yellow fever virus (YF 17D) in mouse brain enhance neurovirulence and cause a reduction in survival time after intracerebral inoculation of experimental mice [37]. The severity of infection shows increased neurovirulence, which may occur due to virus invasion in nerve cells mainly in brain. It also shows inflection of virus in spreading route, mainly in neuroaxis, brain, and spinal cord [37]. More exceptionally, an adjacent stem loop structures has been identified within the JRES and internal ribosomal entry site that cooperatively determine neuro-pathogenicity [27]. There might be some other possibilities, which cannot be denied. For example weaker interactions between virus antigens and host immune cells generate chances of more neuronal invasion by virus that may lead to high pathogenesis. In such a condition both cellular and humoral responses cannot strike well upon virus and its generated molecules, and even body own infected cells.

1.3. Early Symptoms. After transmission of virus to a healthy human being, it travels to various glands and multiplies. It shows an incubation period of 5 to 15 days and then enters the bloodstream. Ultimately, the virus settles in the brain, where it starts culturing and imposes serious problems. Just after inoculation of JE virus in human, it starts replication in Langerhans dendritic, skin cells and migrates to draining lymph nodes [20]. At this vary stage viral infection and disjunctive power of body cells and other factors play important role in development of an early immune response. As soon the infection reaches to secondary lymphoid tissue viremia spreads to visceral organs for example liver, kidney, and spleen. Virus escapes form blood, avoids targeting immune system, and transported to brain and spinal cord via a 
hematogenous route. It also crosses the blood brain barrier by passive transport after active replication in epithelial cells or by infected inflammatory cells.

Moreover, tissue covering the brain and spinal cord (the meninges) becomes infected and swollen. At this stage, JEV infected patient, develops a stiff and painful neck. By day two or three, the patient feels fever, severe headache, nausea, and vomiting. Other major symptoms, mostly observed in patients, include swelling in the brain, loss of balance and coordination, paralysis of some muscle groups, tremors, seizures, and lapses in consciousness. The patient's face shows a stiff mask-like appearance due to heavy dehydration and loses weight. Patients continue to have extremely high fevers and their symptoms get worse. Further, rising body temperature and brain dysfunction carry patient in coma and lead to death in 7-14 days. Those patients who recovered showed permanent neuronal disabilities due to brain damage and face lifelong neurological defects such as deafness, mental retardation, emotional liability, and hemiparesis. The first step in virus infection requires interaction between the virus attachment proteins (VAP) and cellular receptors. The interaction of VAP and its cellular receptors is known to contribute to host range, tissue tropism, and viral pathogenesis. The characteristic and function of virus receptor, once ascertained, may ultimately lead to the production of effective antiviral agents. But cellular receptors for JEV on the host cells are still unknown.

1.4. Pathogenesis. Soon after incubation JE virus starts growing in nerve cells, replicates enormously, challenges the body immunity, and generates severe pathological changes in man. It escapes from blood stream and transfers to neuronal cells by hematogenous route, replicates peripherally, causing a transient viremia before crossing the blood brain barrier or cross through cerebrovascular endothelium or via the olfactory nerves. Virus avoids exposure of body's natural immunity, imposes neuropathogenesis, and generates neurotrophic effects that result in encephalitis syndrome or acute susceptibility to CNS [27]. It starts invasion and destruction of immune cells by cytolytic mechanisms, mainly targets NCPs (neural progenitor cells) pools $[38,39]$ and inhibits the growth and proliferation of these cells [40] by blocking the cell cycle progression [41]. It also targets cerebellar Purkinje cells and causes neurological signs such as ataxia $[42,43]$. More exceptionally infected nerve cells activate uninfected brain macrophages to produce IFN- $\beta$ and supports T cells for production of IFN- $\gamma$, which mediates noncytolytic viral clearance [44]. Further, virus secretes proteins/factors and makes cytokine imbalance and suppresss MHC I present on the membrane surface.

JE virus invades normal body cells, generates antiviral responses, and causes multiple pathological changes inside host. It causes large neuronal cell death and activates microglial cells and makes robust inflammatory attack [45, 46]. Microglial cells are the resident immune cells of the central nervous system (CNS) that have a critical role in host defense against invading microorganisms. Upon activation these cells secrete cytokines, such as interleukin-1 (IL-1) and tumor necrosis factor alpha (TNF- $\alpha$ ), which can cause toxic effects in the brain. These cells also secrete other soluble factors such as neurotoxins, excitatory neurotransmitters, prostaglandin, reactive oxygen, and nitrogen species which make pathogenesis more intense. Thus, pathogenesis of flavivirus encephalitis appears to be a combination of direct virally mediated cell damage and the host inflammatory response [47] that leads to sharp decrease in NCPs cell number [41] and substantial neuronal injury due to neuronal apoptosis in patients [48]. AT this stage virus escape from blood stream avoids exposure of body's natural immunity. It generates neurotropism [49] and causes severe neuropathogenesis like cytomegalovirus which targets and infects embryonic NPCs, start replicating enormously and inhibits their growth and differentiation [40]. It directly affects learning, memory [50, 51] and imposes long-term cognitive defects/disorders like motor and behavioral impairments (neurological sequelae) in surviving early age children or in neonates [41]. Similar invasion NCPs were also made by HIV infection and lead to quiescence in these cells $[52,53]$.

\section{Flavivirus Generated Immune Responses}

2.1. Innate Immune Responses to JEV. In response to JEV infection, body cells manage to operate a nonspecific defense or innate immune responses. However, after interacting with virus infected body cells stimulate and start production of many cytokines type 1 interferons, including TNF $\alpha$ and interferon $\gamma$ which act synergistically, exert powerful effects on the cells and organs, and inhibit virus replication, by inducing an inflammatory response. Further, binding of IFN $\alpha$ and $\beta$ to NK cells generate lytic activity and kill virally infected cells. Further, antiviral activity of NK cells is also greatly enhanced by IL-2 a cytokine that is produced very early in response to viral infection. IFN- $\gamma$ activates macrophages that result in increased expression of class II MHC molecules that also increase cytokine production and enhance microbicidal activity [44]. It also mediates innate immune response and confers antiviral protection to neighboring cells. Further cytokines also induce production of ICAM1 and ELMF and class I MHC molecules which also help to subside the infection. Thus up to some extent, innate immunity seems to fight against JEV, which is manifested by an elevated level of alpha interferon, but treatment with interferon alpha did not improve the patients [54]. Similarly, sialokinin-1 a salivary protein acts as an immunomodulatory factor that is secreted from salivary glands of Aedes aegypti or Culex pipiens mosquitoes that up regulate the $\mathrm{TH} 2$ cytokines, IL-4 and IL-10 and down regulate IFN- $\gamma$ production [55]. It enhances virus replication and transmission [56].

Further, virus and virus infected cells are killed by large granular lymphocytes or polymorphonuclear cells in blood stream and inside other tissues by phagocytosis. These cells are activated by lymphokines/cytokines secreted in response to virus and attracted towards infection site by complement system, a multicomponent enzyme cascade. Besides it, neutrophils, macrophages, and monocytes opt and use antimicrobial chemical secretions for oxidative and nonoxidative attack and try to make a multipronged, highly effective 
coordinated defense. However, both oxygen dependent and oxygen-independent microbicidal activities also help to kill virus. Meanwhile, both reactive oxygen species (ROS) and reactive nitrogen species are generated by NADPH phagosome oxidase enzyme complex (Phox) that assists in mass killing of virus. Further, neutrophils migrate from the blood to site of infection with a vast array of weapons. These cells display several toll-like receptors on their surfaces and can directly recognize virus, bind to it, and show phototropism or marked the virus by the attachment of antibody, complement components, or both. Other defense mechanisms, which are operated, involve the acute phase proteins such as Creactive proteins that help in anti-inflammatory response against virus infection. Thus, wide ranges of innate immune mechanisms operate to eliminate the virus invasion, but fast increase in virus population and repeated exposure of viral proteins exacerbate pathogenesis and cause immune deprivation of cells and sharp decrease in soluble factors.

2.2. Adaptive Immune Responses to JEV. Adaptive immune responses generated are highly specific; these display antigenic specificity, diversity, immunologic memory, and self/non-self recognition. First of all antigenic epitopes are identified by antibodies, and viral proteins are subjected to cross-check by surface receptors of immune cells and secreted signal molecules. In addition, for establishing vital molecular interactions, immune system generates diversity of virus antigen recognition molecules. Hence, at a time immune cells can differentiate between two protein molecules secreted from two different viruses. Both lymphocytes and antigen presenting cells cooperate in adaptive immunity. However, antigen loaded normal B-lymphocytes converted to effector plasma cells. They clonally expanded by repetitive cell divisions and the start secretion of hundreds of antibody molecule per second. Secreted antibodies function major effector molecules of humoral immunity.

However, these antibodies in coordination to complement proteins cause destruction of viruses by direct lysis of the virus particle or by opsonization and elimination of the virus by phagocytic cells [57]. But JEV opts strategies to evade complement mediated destruction and secrete proteins that bind to the $4 \mathrm{~b}$ complement component and inhibit the classical complement pathway [58]. Thus JE virus also tries to escape immune attack or any defense operation by constantly changing their antigens especially epitopes or makes antigenic variations to transform itself to a new locally adapted strains which might be more capable to cause high intensity infection [59]. Thus, on one side virus modifies itself and proceeds through significant mutations done in neurovirulent determinant proteins or its domain, while on other side, it tries to skip off host body defenses. Further, in absence of protective immunity newly developed/emerged viral strains cause more lethal epidemics of encephalitis [54]. Thus, humoral immune responses play a central role in protection against JEV in human and nonprimate subjects but a quick failure of the antibody operated defense breaks down humoral immune response, which also results in early death of JEV infected patient. Further, cellular immunity also makes initial defense against JEV by recognizing infectious agents by cellular receptors CD8 and CD4 located T cells [60]. However, in response to JEV infection both innate and adaptive immune responses are activated which have been shown to reduce serum viraemia and viral loads in infected tissues.

In addition, interactions between receptors on macrophages and microbial components generate soluble proteins that stimulate adaptive immune responses which facilitate elimination of virus. After a $\mathrm{T}_{\mathrm{H}}$ cell recognizes and interacts with an antigen-MHC class II molecule complex, the cell activated and undergoes metabolic transformation and begins to secret various cytokines. The cytokines (soluble proteins) react with receptors on various cell types and induce the cells to start synthesis of new factors or to undergo differentiation. Finally, signal communication is involved between a soluble molecule and a cell membrane bound receptor molecule or between membrane bound molecules located on two different cell types. In a similar fashion antigen, presenting cells interact with $\mathrm{T}$ cells, which activate cell mediated and humoral immunity in patients.

2.3. Cell Mediated Immune Response to JEV. Cell mediated immunity plays important role in mass killing of virally infected cells. It is important for virus control and clearance. It is coordinatingly operated by secretion of IFN- $\gamma$ by $T_{H}$ or $\mathrm{T}_{\mathrm{C}}$ cells. An unexposed or naive $\mathrm{T}$ cell, which is incapable of killing virus (CTL) exposed to virus-secreted antigens, converted into infection, induced CTLs with the help of IL2. Now, it expresses a variety of effector molecules on it and generates strong cytotoxicity to virus [61]. These effector CTLs can recognize antigen class I MHC complexes on specific target cells and destroy large number of virus infected cells after proliferation [62]. Contrary to this, flavivirus antigens restrict CTL release and inflammatory cytokines after exposure to flavivirus infected cells [60, 62]. In addition, antigenic variations among flaviviruses evade the immune response by causing generalized immune suppression of $\mathrm{B}$ and $\mathrm{T}$ lymphocytes or macrophages. It results in destruction of immune cells by cytolytic mechanisms, which alter the function of these cells or make cytokine imbalance or suppression of MHC I on membrane surface [63-65]. Simultaneously, viral proteins may bind to MHC class I molecules within the endoplasmic reticulum and prevent its translocation to the cell membrane. There is another possibility that the viral proteins may inhibit the signal transduction by protein kinase $\mathrm{C}$ during $\mathrm{T}$-cell activation [66]. That is why due to coordinating enzyme membrane attack virus succeeds to lyses to a broad spectrum of cells [67]. Similarly, suppression of T-cell function was observed in spider monkeys, which were normally found resistant to JEV induced disease but have shown susceptibility to other viruses [68-70]. Thus, cell mediated immune response made by CTLs and effector molecules kill virus infected cells, while NK cells and macrophages kill virus cells by antibody-dependent cell mediated cytotoxicity (ADCC). Thus NK cells form first line of defense against JE viral infection (see Table 1).

More exceptionally, JEV specific T-cell responses are mostly observed in peripheral blood mononuclear cells 
TABLE 1: Suppressive effects of different JE viral proteins/antigens, its neurovirulence, and host immune responses.

\begin{tabular}{|c|c|c|c|c|}
\hline Type of protein & Virus type & Neurovirulence & Proposed mechanism & References \\
\hline NS and $S$ & YFV & High & Passive immunization & {$[10]$} \\
\hline NS1/NS3 & JEV & High & Passive immunization & {$[9]$} \\
\hline NS4/NS2B-3 proteinase & YFV & Mild & $\begin{array}{l}\text { Cross-neutralizing } \\
\text { antibodies }\end{array}$ & {$[3,8]$} \\
\hline NS gp 48 & $\begin{array}{l}17 \text { D YFV, } \\
\text { DNV }\end{array}$ & High & $\begin{array}{l}\text { Passive and active } \\
\text { immunization }\end{array}$ & {$[11,14]$} \\
\hline DNA 4 S & $\begin{array}{c}\text { Rec vaccinia } \\
\text { virus }\end{array}$ & High & Passive immunization & {$[12]$} \\
\hline E or NS1 & JEV & High & Protective immunity & {$[13]$} \\
\hline NS1 & JEV & High & $\begin{array}{l}\text { Elicits DNA } \\
\text { immunization }\end{array}$ & {$[17]$} \\
\hline \multirow[t]{2}{*}{ M protein mutant } & VSV & Low & Passive immunization & {$[25]$} \\
\hline & & Infection & Treatment/proposed mechanism & References \\
\hline \multicolumn{5}{|c|}{ Cell mediated immune response } \\
\hline \multirow[t]{3}{*}{ NS and $S$} & JEV & High & CTL recognition of virus & {$[61]$} \\
\hline & & & Action of NK/cytotoxic T cell & {$[62]$} \\
\hline & & & JEV-specific murine CD8+ cytotoxic T lymphocytes & {$[70,72]$} \\
\hline \multirow[t]{2}{*}{ NS and S } & $\begin{array}{l}\text { JEV and } \\
\text { other viruses }\end{array}$ & High & Passive transfer of immune spleen $\mathrm{T}$ cells & [73] \\
\hline & & & MyD88 adaptor molecule-dependent/independent pathways & {$[94]$} \\
\hline \multirow[t]{4}{*}{ Virus protein } & $\begin{array}{l}\text { JEV and } \\
\text { other viruses }\end{array}$ & High & JEV Th1 and Th2 cytokines & {$[55]$} \\
\hline & & & Anti-inflammatory cytokine & {$[83,86]$} \\
\hline & & & Interleukin-10, endogenous IL-10 production & {$[89,90]$} \\
\hline & & & Natural antibodies and complement & {$[58,60]$} \\
\hline \multicolumn{5}{|c|}{ Humoral immune response to JEV } \\
\hline NS1 protein & JEV, DNV & High & Protective immunity & {$[102]$} \\
\hline \multirow[t]{3}{*}{ NS1 } & JEV & High & DNA immunization with NS1 elicits protective immunity & [103] \\
\hline & & & Virus-specific cytolytic antibodies & {$[104]$} \\
\hline & & & ADCC-dependent cytolysis of virus & {$[104]$} \\
\hline prM and $\mathrm{E}$ proteins & JEV & High & Subviral particle mAbs are highly protective & {$[110,114]$} \\
\hline $\begin{array}{l}\text { SMP* virus-vaccinia } \\
\text { recombinants }\end{array}$ & & High & Induce high levels of protection against JEV & {$[111]$} \\
\hline Chimpanzee fabs & JEV & High & Humanized monoclonal antibodies & {$[112]$} \\
\hline \multicolumn{5}{|l|}{ Other mechanisms } \\
\hline & & & Antiviral actions of interferon & {$[132]$} \\
\hline & & & RNA interference & {$[115,118]$} \\
\hline & & & RNA silencing & {$[116,119]$} \\
\hline & & & Complement mediated cytolysis pathway & {$[127]$} \\
\hline & & & T-cell priming & {$[122,123]$} \\
\hline
\end{tabular}

${ }^{*}$ Structural membrane proteins.

(PBMCs) collected from vaccinated as well as from JEV infected patients [71]. From such patients both CD4+ and CD8+ T-cell subsets directed against structural proteins were identified in vaccinated patients. In contrast, PBMCs from JEV patients showed CD4+ and CD8+ responses to nonstructural (NS) or C proteins. Hence, nonstructural proteins especially NS3 seem to play a major role in the initiation of T-cell responses and is the major target of JEV-specific cell mediated immune responses. Contrary to this nonstructural protein NS1 is weakest one and does not show any T-cell response. Further, cytolytic CD4+ T-cell clones generated from PBMCs of individuals immunized with inactivated JEV 
vaccine [72] were found flavivirus cross-reactive in nature. But, significance of such CD4+ T cells is still unknown in vivo. Furthermore, NS3 stimulates IFN- $\gamma$ production by both the CD4+ and CD8+ T cells. It also shows Th1 immune response, which is a critical determinant of immune control during JEV infection $[73,74]$. Further, recombinant JEV domain III has also been shown to elicit a Th1 type of response in Balb/c mice [75].

Further, lifelong cell mediated immunity could be obtained by passive transfer of immune spleen $\mathrm{T}$ cells in $\mathrm{T}$ cell deficient animals [76]. In such animal models $\mathrm{T}$ cells are supposed to be required for recovery [77] and protection against JEV generated lethal challenge [78]. However, when thymus deprived mice were inoculated with JEV they showed an impaired anti-JEV antibody response, but T-cell responses in generating B-cell immunity following an JEV infection are highly important [79]. Alternatively, JEV primed purified $\mathrm{T}$ cells administered into newborn mice by intracerebral (i.c.) route along with 10x LD50 JEV have shown protection [78]. Hence, there is much possibility that among $\mathrm{T}$ cells, a population of $\mathrm{CD} 4+$ and $\mathrm{CD} 8+\mathrm{T}$ cells is necessary for operating protection from JEV and depletion of either population abrogated the protective ability of transferred effectors $[61,66]$. It proves that only $\mathrm{CD} 4+$ is required for protection in spite of CD8+ T cells. But it was declined by other researchers who propounded that neither enriched JEV primed $\mathrm{T}$ cells nor $\mathrm{B}$ cells were found able to protect mice from JEV infection [80]. But it is possible that CD8+ T-cell activation can contribute to diminish disease pathogenesis or immune pathogenesis in the case of other flaviviruses and dengue virus [81]. Further, in knockout mice, immunized with envelope DNA vaccine showed protection abrogated only in Ig and CD4+ cells.

Normally in human JEV infected macrophages as well as dendritic cells are two different antigen presenting cells of the immune system which play dual role. Further, activated $\mathrm{T}_{\mathrm{H}}$ cells produce a number of cytokines, including IL2, IFN- $\gamma$, TNF $\alpha$, and IL-6 [82] which could altered cellular function of JE virus [83] and defend host against virus attack. These effector molecules help to establish cell mediated immune response by generating CD8 Tc cells and CD4, TH1 cells which start operating antiviral defense [75]. It also results in increase in IL- 4 and TNF $\alpha$ levels in the serum of JEV challenged animals [84] and increase in the expression of all these cytokines in the spleen [85]. Thus, both TNF- $\alpha$ and IFN- $\gamma$ could be involved in rapid virus clearance from the periphery, and they could exacerbate inflammation within the CNS [85]. Among which, IFN- $\gamma$ induces an antiviral state in cells while IL-2 acts indirectly to convert more number of CTL precursors into an effector T-cell population [85]. These in coordination to IL- 2 and IFN- $\gamma$ activate natural killer cells (NK cells) that could eliminate virus infected self cells and large number of virions $[65,86]$. Further, double stranded dsRNA molecules generated during virus life cycle induce IFN- $\alpha$ and IFN- $\beta$ which help to eliminate virus infected cells. Similarly, E protein of JE as well as nonstructural proteins expressed by the uninfected cells serves as targets for killing CTLs [67]. Further, complement activated cytotoxic lymphocytes with help of antibody molecules can kill large population of virus and virus infected cells and work as a second line of defense.

Normally in human JEV infected macrophages as well as dendritic cells are two different antigen presenting cells of the immune system which play dual role. After having virus infection, these cells become active and start generation of several types of cytokines [82] which could altered cellular function of JE virus [83]. However, DC maturation is associated with increased antigen presentation, increased synthesis and secretion of proinflammatory cytokines such as TNF $\alpha$, IL-12, and IL-6, upregulation of costimulatory molecules such as CD80, CD86, and CD40, and alteration of chemokine receptors [87]. Further, presence of toll-like receptor (TLR) molecules over cell surface helps to recognize pathogen and in generation of innate immune responses. Contrary to this JEV infection of DCs increased the secretion of IL-10 [88] TNF $\alpha$, CCL2, and I IFNs. These are recognized crucial modulators of viral endogenous level of IL-10 [89, 90]. Further, JEV stimulated DC function may suppress Foxp3+ Treg cells and help in establishment of JE disease [91]. In addition highly efficient vaccine strain of JEV triggers both innate and adaptive immunity and shows depletion of splenic CD $8 \alpha+$ CD11c + DCs as well as suppression of MHCI mediated antigen presentation leading to suppression of CD8+ T cells [92]. Thus, DCs play a critical role in antigen presentation and initiation of adaptive immune responses against viruses through TLRs, which are expressed on the cell surface or in intracellular locations. Therefore, functional impairment of DCs, CD4+, and CD8+ T cells by JEV results in generation of severe immune pathological [93] changes in patients that leads to a severe CNS diseases [94]. Thus, JEV infection of macrophages resulted in increased synthesis of cytokines and costimulatory markers that stimulate cellular community.

2.4. Humoral Immune Response to JEV. Humoral immune responses play a central role in protection against JEV in human and nonprimate subjects. It starts after identification of virus by $\mathrm{T}$ helper cells, which quickly respond to viral antigens. In combination to macrophage, $\mathrm{T}_{\mathrm{H}}$ cells display and present viral antigens to $\mathrm{B}$ cells. These antigen loaded B cells converted to plasma cells which clonally expand and start secretion of antibodies after 7-8 days of virus infection. Thus, an antibody mediated humoral immune response starts which tries to control the infection by binding to host cell membrane molecule. Antibody molecules block viral penetration by binding to epitopes that are necessary to mediate fusion of the viral envelope with the plasma membrane. If the induced antibody is complement activated or bound, both can agglutinate viral particles and function as an opsonizing agent to facilitate $\mathrm{Fc}$ or $\mathrm{C} 3 \mathrm{~b}$ receptor mediated phagocytosis of the viral particles. However, neutralizing antibodies from JEV infected cells leads to inhibition of virus replication and diminishes cytopathic effects generated by virus. After sound interactions of structural and non-structural proteins generated by JE virus interacts with the body cells and triggers immune responses in host 5-7 days after infection.

Flavivirus infection evades immune response mainly in responder cells. It is the main reason that different patients 
may show different immune responses to JEV infection. There is a possibility that immune responses may control virus transfer at an early stage, but due to presence of virus secreted inhibitory molecules a quick failure of the antibodyoperated defense occurs that breaks down humoral immune response and results in death of JEV infected patients. Naturally, large numbers of IgM molecules are secreted in the cerebrospinal fluid (CSF) of patients within 5-7 days, which are positive prognostic indicators or markers of JEV generated infection. Further, its level raised in the serum and CSF of most symptomatic patients [95]. Its maximum level was obtained day 9 onwards after the onset of clinical disease that can be diagnosed by anti-JEV IgM capture ELISA $[96,97]$. This primary IgM response leads to class switching and production of IgG by 30 days after infection only in patients who survive. Thus, both $\operatorname{IgM}$ and IgG humoral immune responses effectively work to subside the flavivirus infection. Hence, neutralizing antibodies alone are sufficient for conferring protection against JEV challenge at initial stage. A failure in production of IgM led to more lethal consequences in JEV infected infants in comparison to children more than 8 years of age. Therefore, a passive immunization of patient by using neutralizing monoclonal antibodies raised against E protein can protect patients and experimental animals from lethal virus challenge [98, 99]. More specifically, antibodies generated against E and NS1 proteins generate both cell mediated and humoral immune responses that help to sub-side the virus infection $[100,101]$.

Furthermore, monoclonal antibodies synthesized against many nonstructural proteins were found protective in nature except anti-NS1 antibodies. These anti-NS1 antibodies could provide only low level of protection from JEV infection. However, E. coli expressed NS1 protein induces protective humoral immune response in mice [102] and causes antibody-dependent complement mediated cytolysis of the JEV infected cells [103]. More specially, subviral particles consisting of prM in addition to $\mathrm{E}$ proteins were found highly effective in generating a protective immune response in normal mice $[101,104]$; those which lack immunoglobulin synthesis were died [80]. Hence, anti NS1-antibodies can directly affect reduction in virus titers from infected cells [105]. Similarly, humanized monoclonal antibodies generated against different domains of $\mathrm{E}$ protein and derived from chimpanzees protect mice from lethal JEV challenge. These protective antibodies also exhibit high neutralizing activity against a broad spectrum of JEV genotype strains [106]. Similarly immunization of mice with recombinant vaccinia viruses that express various JEV gene products such as E, prM, M, and NS1 conferred protection against lethal JEV challenge in mice $[107,108]$. Similarly, oral immunization of mice with live JE vaccine also generates brisk and shows protective immune responses in albino mice, but low titers of neutralizing antibodies could not be found much protective [109].

In addition, passive transfer of virus-specific antibodies kills JEV and slows down the cell invasion and infectivity via Fcy or complement receptors [110]. Thus, neutralizing antibodies try to decrease the virus load and infectivity. However, virus generated particles evoke an early immune response in host which is also enhanced later on either vaccination or by virulent proteins [111]. There are chances that low intensity protective immune responses generated may cause high pathogenicity and abnormality in the host, but no report is available on antibodies enhancement of neurovirulence except viral E protein. Contrary to this, monoclonal antibodies (MAbs) synthesized in response to virus envelope glycoprotein [112] showed enhancement of neurovirulence [110]. This enhancement of neurovirulence arises because of an interaction between viral antigen and antibody [110] and is noted in mice after vaccinating with DNV [113] and YFV [110] flaviviruses. More specially, antibodies do not protect virus infection during acute phase of infection, because they remain incapable to eliminate the virus because virus is integrated into host chromosomal DNA. More exceptionally, JE virus uses a variety of strategies to escape destruction by the adaptive immune system, reduces its own antigenicity either by growing within host cells or being sequestered from immune attack by shedding their membrane antigens. Even in the absence of antigen, specific antibodies complement proteins in serum start deportation of protein fragments on the surface of intruding pathogens that facilitate binding of neutrophils by rapid phagocytosis.

\section{Control of Flavivirus Infection}

3.1. Inhibition of Innate Immune Response. Flaviviruses secrete potential inhibitory proteins or factors which stop formation of IL-12 cytokine production and start inhibition of binding of IFN $\alpha$ and IFN $\beta$ to NK cells. Virus multiplication raises the level of inhibitory proteins that enhance lytic activity of body cells that makes severe obstruction in innate immune defense. Virus infection primarily does inactivation of the type I interferons (IFN- $\alpha$ and IFN- $\beta$ ) and tries to inhibit receptor interactions with immune surveillance cells. Similarly, hepatitis $C$ virus secretes proteins which inhibits IFN activity and blocks the transcription response to IFN $\alpha$. But few receptors located on macrophages such as TLR3, TLR 7, and TLR 8 help to recognize JE viral infection, while ARP proteins (Proteins of acute phase response) contribute and few pro-inflammatory cytokines such as TNF $\alpha$, IL-1 and IL-6 send major signals for induction of innate immune response. In addition, circulating lymphocytes cause an elevation in IFN alpha level in plasma and CSF.

Nevertheless, there are some mechanisms, which can provide protection against flavivirus generated neurovirulence and pathogenesis. However, both RNA silencing and interference [114] block RNA replication inside host cells and provide protection against viruses [115]. More especially, few inhibitory proteins and minor protein factors do RNA silencing and inhibit virus infection $[116,117]$. Further, rapid and specific degradation of RNA takes place in the cytoplasm that acts as a strong weapon against viruses [118]. It suppresses chemokine receptors and allows inhibition of virus replication [119]. Moreover, accumulation of Si RNA potentially induces sequence-specific degradation of viral proteins through a specific cellular RNAse. Similar antiviral activity is also detected in animal and plant cells in which expression of virus derived transgenic mRNA sequences start degradation 
of viral RNA. Moreover, exogenous expression of Si RNA may also start in decrease in viral RNA of some viruses such as west Nile virus, HIV, Influenza, and HCV. RNA possesses divergent sequence and target silencing pathway and shows antigen expression. However, in flaviviruses RNA replicates in endoplasmic reticulum where no RNA activity occurs; therefore it is very difficult to naïve the virus. Further, at this stage it is very difficult to find the route of virus/infection transfer to CNS passing through blood brain barriers and manage to escape innate immune mechanism; therefore local factors cannot act upon hardly against virus.

3.1.1. Activation of Complement System. The complement system is a multicomponent enzyme cascade of serum proteins that is also used to attract phagocytic cells to the viruses and for their engulfment by phagocytosis. Viruses are obligatory intracellular parasites and depend solely on the host for their survival and propagation. These invade the host and try to hamper the activity of complement system of the host by secreting inhibitory proteins/factors. But these complement proteins possess multicomponent system that is why virus could not make inhibition of major pathways that exist in host cells. Therefore, the complement system presents a constant threat to viruses for their survival within the host and inhibits successful virus transmission. It may help in complementdependant viral lysis, neutralization of the viral particles by opsonization, and help to operate destruction of the viral particles by phagocytosis [120]. These pathways also have key role in opsonization of bacteria, activation of inflammation, and clearance of immune complexes. However, interaction of complement proteins and protein fragment with receptors on cell of the immune system has important role in innate and adaptive immune responses [121].

Complement proteins also work through antibodydependent and antibody-independent pathways of complement system in a joint operation form membrane attack complex and results in destruction of viral antigens or virus particle [120]. Though few complement proteins that occur in inactive form, are activated by three different complement pathways that is classical, alternate and lectin binding and start working against viruses [122]. Cells infected by viruses can express on their membranes viral antigens long before the viral assembly takes place. If a CTL and a suitable antibody are being made available with supporting active complement proteins it destroys large population of virus. It is a very effective mechanism, which helps in mass destruction of virus-infected cells by using antibodies (antibody-dependent cell mediated cyto-toxicity ADCC system), classical pathway of complement activation, phagocytosis, and cytotoxicity mediated by CD8+ lymphocytes. Thus, formation of antigenantibody complex stimulates the Fc receptor on macrophages (CTLs) that helps in viral clearance and evokes heavy complement mediated cell lysis of virus or virus infected cells.

However, in response to a virus attack, complement induces synthesis of proinflammatory peptides (3a and 5ca) which help to reunite and activate monocytes and granulocytes to the inflammatory site. Further, proteolytic fragments C3 (C3b, C3bi, C3d, and C3dg) promote uptake by cells that express complement receptor [122]. In this process $\mathrm{C} 3$ convertase enzyme helps and catalyzes the reaction. Thus after amplification hundreds of $\mathrm{C} 3 \mathrm{~b}$ molecules are generated which bind to nearby cells, mediate damage to healthy cells by opsonization to phagocytic cells [123]. C3b receptors help to form membrane attack complex. There is another possibility that C3 fragment enhances viral antigen uptake, facilitate antigen presentation by macrophages and DC, and induces specific antibody production and T-cell proliferation [124]. More specially, C3b, C4b, and C3bi fragments play important role in opsonization of antigen, while $\mathrm{C} 3 \mathrm{~b}$ and $\mathrm{C} 5 \mathrm{~b}-9$ help in neutralization of virus, while C3b, C5a, and C5b 67 cause extravasations and chemotaxis of neutrophils and monocytes [125].

Furthermore, both alternative and lectin pathways are antibody-independent major pathways, which are initiated by the reaction of complement protein with surface molecules of microorganisms. These mainly consist of complement activation that involves four serum proteins $C 3$, factor $b$, factor $\mathrm{D}$, and properdin. The $\mathrm{C} 3 \mathrm{~b}$ present on surface of foreign cells can bind another serum protein $\mathrm{B}$ and form a more stabilized complex by binding to $\mathrm{Mg}+$ ions. This binding to $\mathrm{C} 3 \mathrm{~b}$ expression site on factor $\mathrm{B}$ may serve as substrate for protein $\mathrm{D}$ and cleaves the $\mathrm{C} 3 \mathrm{~b}$ bound factor $\mathrm{B}$ and releases fragment $\mathrm{B}$ that diffuses among generating $\mathrm{C} 3 \mathrm{~b} \mathrm{Bb}$. There is another possibility that unhydrolyzed C3 may produce more $\mathrm{C} 3 \mathrm{~b}$ that deposits on an antigenic surface with in no time. Further, C3 convertase activity generates $\mathrm{C} 3 \mathrm{~b} \mathrm{Bb} 3 \mathrm{~b}$ complex that shows $\mathrm{C} 5$ convertase activity, and nonenzymatic component binding occurs to form $\mathrm{C} 3 \mathrm{~b}-\mathrm{C} 5$ and $5 \mathrm{~b}$ component that commence first phase of lytic cycle [126]. In this process, complement pathway that is opted by virus is still unknown. This contact target inhibition of complement-mediated pathway chosen by flavivirus may help to finish the infection. There is a possibility that few viruses may generate infection only in patients, which are C3 deficient [124].

3.1.2. Classical Pathway. The classical pathway is initiated by antibody binding to a cell target reactions of $\operatorname{IgM}$ and $\operatorname{IgG}$ subclasses. In classical pathway complexed antibody activates phagocytic cells. But a single antibody molecule complexed to the microorganism is not enough to kill it because it cannot cause the cross linking of antibody receptors in the phagocyte surface membrane which is required to activate the cell. If it is operated by three or four antibody molecules bound to a bacterium or a virus close together, these can attract macrophage thousand times much strongly than a single antibody. When an antibody bound to a microbe, it links to complement sequence Clq, it is polyvalent molecule and contains central collagen-like stem branching into six peptide chains each tipped by an antibody-binding subunit. Clq is associated further with two subunits, C1r and Cls, which are stabilized by $\mathrm{Ca}++$ and form a trimolecular complex and which acquires proteolytic activity. Further, it allows to act on the next component in the chain $\mathrm{C} 4$ which undergoes cleavage and divides in to $\mathrm{C} 4 \mathrm{a}$ and $\mathrm{C} 4 \mathrm{~b}$ under the activity of multienzyme cascade; then several molecules of $\mathrm{C} 4$ bind to the antibody $\mathrm{C}-1$ complex or to the surface of microbe 
itself. Further, in the presence of $\mathrm{Mg++}, \mathrm{C} 2$ can complex with $\mathrm{C} 4 \mathrm{~b}$ and form a new product $\mathrm{C} 4 \mathrm{~b} 2 \mathrm{~b}$ that shows vital C3 convertase activity that is essentially required to activate $\mathrm{C} 3$ with the same specificity as the $\mathrm{C} 3 \mathrm{bBb}$ is generated by the alternative pathway. Now a strong membrane attack complex is formed with the help of C3, C3b, and C4b2b in addition to $\mathrm{C} 5$ splitting enzyme. Just as the alternative pathway $\mathrm{C} 3$ convertase is controlled by the factors $\mathrm{H}$ and $\mathrm{I}$, so the breakdown protein $\mathrm{C} 4 \mathrm{~b} 2 \mathrm{~b}$ is brought about by either a $\mathrm{C} 4$ binding protein (C4bp) or a cell surface $\mathrm{C} 3 \mathrm{~b}$ receptor (CR1) in the presence of factor I. Finally, the alternative pathway of complement activation works very effectively and leads to heavy destruction of the viral particles. Thus, all three pathways converse in a common sequence of events and cause heavy cell lysis of microbes. In addition, secretory IgA blocks binding of virus to host cells and prevents infection, while IgG, IgM antibodies block fusion of viral envelope with host cell's plasma membrane. These also enhance phagocytosis of virus particles or opsonization. In addition, IgM antibodies also do agglutination of virus particle. With this, complement activated by IgG or IgM antibody mediates opsonization by $\mathrm{C} 3 \mathrm{~b}$ and lysis of enveloped viral particles by membrane attck complex. Antimicrobial peptides are important effectors of innate immunity; these kill a wide variety of microorganisms and disrupt microbial membranes.

Even after presence of a well-organized effective complement protein cascade system, viruses opt various ways to subvert the complement attack; either by capturing CCPs (complement cascade proteins) from the RCA loci of their host, or by evolving CCPs within their genome. In addition, they take advantage of the complement system and use the host complement receptors to infect various cells [127]. Some viruses encode proteins that modulate and inhibit the host's complement function, while others pickup the host's complement regulatory proteins to do the same, and still others use complement receptors to gain cellular entry. Therefore, there is an urgent need to identify vital structural determinants of immune evasion molecules of virus that are important in interacting with complement proteins.

\subsection{Use of Virus Neutralizing Antibodies. Neutralizing anti-} bodies generated in response to virus antigens provide protection against JEV. It plays important roles in determining viral pathogenicity and cellular profusion [10]. These antibodies easily recognize viral surface antigens and play crucial role in spread of virus during acute infection and in defense making against reinfection. Flavivirus may bind to surface receptors in cell membrane glycol proteins and glycol lipids and express them. It may help them to initiate infection by binding specifically to host cell membrane molecules. It is well known that in response to JEV infection, the host produces virus neutralizing antibodies which prevent the virus from entering the cells, while viral agglutination_(IgM) reduces the number of infectious agents. Thus virus neutralizing antibodies agglutinate viral particles and function as an opsonizing agent to facilitate $\mathrm{Fc}$ or $\mathrm{k} 3 \mathrm{~b}$ receptor mediated phagocytosis of the viral particles. Such neutralizing antibodies also limit dissemination of infection and mediate humoral immune defense by binding to flavivirus pathogenic antigens. Contrary to this, passive transfer of these polyAbs or MAbs against yellow fever virus pathogenic antigen/proteins could not successfully protect mice against lethal challenge [128], while virus antigen-specific antibodies synthesized inside host operate through receptor binding to neutralize the virus attack. Thus, mAbs generated against NS1 are nonneutralizing but are proved highly effective against virus attack $[129,130]$, showed strong complement fixing activity [110], and cause heavy complement mediated cytolysis of infected cells and show antibody-dependent cytotoxicity (ADCC).

The principal target for the neutralizing antibodies is the E proteins [131], a subset of prM or any other virus associated protein [132-134]. These are proved highly protective to normal body cells $[110,135,136]$. Hence, both Poly Abs and mAbs inhibit viral attachment to host cells or block viral penetration by binding to epitopes that are necessary to mediate fusion of viral envelope with plasma membrane. In addition crossprotective antibodies produced against improved epitope sequences of common determinants of $\mathrm{E}$ and $\mathrm{M}$ proteins have shown some good results. Besides NS1, peptide from JEV E protein that contains virus neutralizing epitope is also used to generate JEV neutralizing antibodies [131]. In addition autoassembled fusion proteins or virus-like particle (VLPs) was prepared by fusing JGMV, coat protein (CP) in E. coli, and [131]. These naturally assembled or recombinant VLPs, which possess JEV peptide sequences, trigger production of virus neutralization antibodies in immunized mice. Such neutralization antibodies generated against VLPs showed significant protection against lethal viral challenge [131]. It also depends on recognition of the peptides in demand and its binding to antipeptide antibodies. If a peptide fused to, a large protein as JGMV that binds to CP may have some constrains on the conformation imposed by the protein. Similarly, improved virus vectored mixed vaccines could provide better protection to JEV infected patients $[15,137-$ 140].

E protein is a major structural protein that contains numerous neutralization epitopes, which mediate attachment of virus to host cells and do membrane fusion and entry of virus into host cell. It contains a putative receptor binding domains that induce the host immune response [22, 23]. E protein also contains one putative $\mathrm{N}$ linked glycoylation site at NS154 $[20,21]$ and plays major role in determination of virulence phenotype, and single amino acid substitutions are sufficient to cause loss of neurovirulence [141, 142]. Furthermore, E (envelope) protein NS3 is the main protein that is responsible for pathogenesis and shows immune response. It is a dominant CD4 and CD8 cell eliciting antigen [78] which is able to induce caspase 3 activation and mitochondria mediated apoptosis in human medulla blastoma cells [143]. It is a nonstructural viral protein that can be used as a candidate molecule for development of any therapeutic antibody or antibiotic [144]. Antibodies synthesized against these proteins may ably suppress the viral replication [70] and proliferation inside host [145].

Furthermore, another protein NS3 that is localized at the JEV induced convoluted membrane and might be synthesized from rough endoplasmic reticulum. It is associated 
with microtubules and may have essential role in viral packing, intracellular transport of viral components, and virus assembly [146-148]. It is a multifunctional protein that plays important role not only in viral replication but also raise immune response and pathogenesis in host. NS1 elicits protective immunity in mice [17]. However, synergistic interactions of anti-NS1 monoclonal antibodies protect passively immunized mice lethal challenge to DEV [130]. Similarly, prM proteins contain critical antigens conferring protective humoral and cellular immunity against JE. It successfully elicits long lived protective immunity against flavivirus [137] more similar to synthetic peptides [140] and recombinant virus secreted peptides [139] with improved epitopes of both $\mathrm{E}$ and $\mathrm{M}$ proteins [138].

Thus, E, prM [132], and any other virus envelope protein [142] that may possess neutralizing domain [137] are right molecules to generate strong protective monoclonal antibodies to control JEV. Hence, molecular characterization of neutralizing domain of the JE virus is highly essential [149]. It will help to identify a significant control point in the antigen molecule that would be used to develop neutralization antibodies and to optimize the chemical production of pharmacological ligands to neutralize the JEV and other disease viruses. Further, a single amino acid substitution in envelope protein $\mathrm{E}$ in JEV leads to attenuation of the mice [150]. However, persistence of neutralizing antibody [151] after a prolonged exposure of virus also helps to detect viral diseases in long term in human population [152], but preexisting neutralizing antibodies increased the symptomatic disease without induction by vaccine dose [149]. Mice with different susceptibility to Japanese encephalitis virus infection show selective neutralizing antibody response [153] but showed Flavivirus-induced antibody cross-reactivity [154]. Virus-specific neutralizing immune response against JE virus is obtained by using chimeric peptides for immunization [155].

Flaviviruses mainly neurotropic viruses such as JEV and tick borne encephalitis virus persist for longer period inside host neurons $[156,157]$ and evolved specific tactics to evade both innate and adaptive immune responses [130]. This is virus capsid which is made up of different types of coat and envelope proteins that are highly antigenic in nature. It induces the production of a large number of antibodies that can have different actions against the virus. Hence, $\mathrm{N}$-linked glycans of viral proteins play important roles in modulating the immune response and help to maintain the appropriate antigenic confirmations and provide neutralization potential epitopes [20, 21]. However, deletion of N-glycosylation sites enhances cellular and humoral immune responses [158]. More specially before synthesis of mAbs topological and functional characterization of epitopes is necessary [10]. However, strong antigens with defined epitopes can be generated by insertion of plasmid encoding JE virus premembrane and envelope genes. In case of artificial synthetic peptides [140], it is very difficult to generate an appropriate neutralizing domain similar to a natural structural virus generated glycoproteins [137]. However, an improved epitope can be designed based on common determinants present in both $\mathrm{E}$ and $\mathrm{M}$ envelope proteins [138].
Therefore, more than the virus and host cell interactions, proper identification of neurovirulent pathogenic peptides is highly essential for generation of more appropriate mAbs. Hence, 3D conformational structure of the virus origin peptides is considered an important determinant of immunogenicity [56]. Therefore, due to antigenic structural confirmatory differences experimental animals show variation in antibody response to different JEV peptides, recombinant proteins, and mutant proteins. It also decides binding of antipeptide antibodies to proper antigen molecule. Further, addition of a linker peptide with protein imposes a significant effect on folding and stability of fusion protein. If such peptides are used without adding to any adjuvant, these might generate strong JEV neutralizing antibodies which may respond more effectively and efficiently against JEV generated lethal challenge in experimental animals. Thus, infectious protein derived peptides are of immense therapeutic importance not only to generate neutralizing antibodies for protection against JEV but also for nullifying the effect of viral antigens by changing their confirmatory structures by replacing amino acids, folding, and chain structure. It may significantly provide a different antigenicity that will help to generate better immunogenicity by producing new potential vaccines and to obtain very high titers of neutralization antibodies in experimental mice.

Both B cells and antibody play critical role in dissemination of infection [130], by secreting important bio-molecules such as inteferons, antibody and complement proteins. Further, both $\mathrm{T}$ and NK cells (natural killer cells) contribute to the control and elimination of viral infections $[130,159]$. Further, protective immunity is also generated by synthesizing monoclonal antibodies against nonstructural proteins which could protect passively immunized animals from lethal challenge of viruses [130]. It is also induced by both DNA based [14] and virus vectored immunization with prM and $\mathrm{E}$ proteins that may elicit long lived protective immunity against the flavivirus $[136,137]$. Further, protection against virus infection is directly proportional to the titer of neutralizing antibodies. Thus both natural antibodies and complement link innate and acquire immunity $[57,58]$ that also curve on neuroinvasiveness [70] and acute necrosis of $B$ cells $[160]$.

3.2.1. Active Immunization by Administering Vaccines. Viral proteins elicit pathogenesis in host by attaching themselves to the healthy cells by receptor binding and establish virus attachment and entry into the host. Therefore, to obstruct the infection at initial stage vaccination of infants and children is highly essential. Though, numerous options of JE treatment are available but vaccines are only a hope for prevention of Japanese encephalitis. Vaccines have shown better efficacy and high safety profile, hence vaccination is only reliable method in comparison to any drug treatment. A proper and timely vaccination reduces the burden of disease and significantly cuts down the rate of JEV generated pathogenesis and mortalities in diseased and undiseased population [161]. Further, regular vaccination can successfully break the annual cycle of disease occurrence in endemic to epidemic areas. It 
is safer treatment that provides wider protection to travelers mainly to outdoor health workers, surveyors, and researchers who get extensive viral exposure in rural areas during their stay in endemic region. It is also recommended for expatriates and migrants living in endemic areas throughout a transmission season or longer. Due to better protection efficacy, vaccines are considered as necessary tool to control JE, but it is a bitter truth that vaccines are not reached/available to the poor countries in Asia [162]. Initially an effective vaccine was prepared in 1941, which was recommended for routine use in endemic countries in 1950s [160]. It has shown good results and found highly successful against JEV control in Japan, Korea, and Taiwan. But due to some inadequate disease surveillance, inconsistent vaccine supply, lack of guidance and support for immunization, and limited advocacy have made obstacles and hampered the JE eradication program in the past [163].

Later on, for achieving much high protection efficacy and feasibility for an effective JE control new vaccines were designed and used for vaccination purposes. In addition, new guidelines of vaccination were implemented by W.H.O with a clear aim to check the disease spread, cut down the disease burden and impact of JE virus on human population living in endemic areas. Hence, new surveillance standards and much advanced diagnostics were developed to fight against the severity of JE disease [164]. To fulfill this aim, new single-dose compatible vaccines were generated and are used for routine immunization of various infant groups. This has made counterfight against JEV more affordable and faster. Further, W.H.O has made immunization/vaccination an integrated part of the public health system and made it essential for school going children. It is much progressively going on in Korea, Japan, China, Thailand, and Taiwan but unfortunately in India routine immunization of school-age children could not become possible due to lack of funds, civic amenities and disease survey [165]. In endemic areas where both mortality and morbidity rates are higher, routine immune diagnosis of JE virus [166], with follow up booster dose of vaccine [166-168] is highly essential for early age infants and children [169].

Recently, Global Vaccine Safety Initiative (GVSI) has launched a strategy to put into practice the Global Vaccine Safety Blueprint. The Blueprint is a plan to ensure the safety of vaccines used worldwide over the next eight years and beyond. The GVSI is supporting the Global Vaccine Action Plan which is a roadmap for vaccination campaigns that aimed at preventing millions of deaths from disease worldwide. The period 2010-2020 has been declared the Decade of Vaccines. The GVSI has been endorsed by the Strategic Advisory Group of Experts (SAGE) on Immunization. SAGE is the principal advisory group to WHO for vaccines and immunization. It is advising W.H.O. on overall global policies and strategies, ranging from vaccines and technology, research and development, to delivery of immunization and its linkages with other health interventions. SAGE is concerned not just with childhood vaccines and immunization but all vaccine-preventable diseases at global level. Based on preparation method and different substrates used JE vaccines are of following types.

\subsubsection{First Generation Vaccines}

(1) Inactivated Mouse Brain Derived Vaccine. A formalininactivated JE vaccine was derived from mouse brain in China in early fifties. It is based either on the Nakayama strain, which was isolated in Japan in 1935 or on the Beijing1 strain [170-172]. It is routinely used for immunization in Japan and several Asian countries. This is the only JE vaccine that is commercially available in the international market [161]. It was largely generated by Japan and its other manufacturers are South Korea, Taiwan, Thailand, and Vietnam. Currently, it is used in China, India, Japan, South Korea, SriLanka, Thailand, and Vietnam. Its three doses $(0.5 \mathrm{~mL}$ each) are required to immunize children on days 0 , 7 , and 30 , followed by a booster at 1 year and thereafter at intervals of 3 years. It is administered subcutaneously in doses of $0.5 \mathrm{~mL}$ or $1 \mathrm{~mL}$, up to age of $1-3$ years. It has shown 9195\% disease preventing efficacy in controlled trials in several Asian countries [173] It is also used to immunize travelers, tourists, and military personnels in south east Asian countries like Thailand, India, Korea, Taiwan, Vietnam, Malaysia, and SriLanka, but it showed numerous side effects comparable to other vaccines [174]. Due to likely interference of maternal antibodies, early aged infants (below 1 year) are avoided to vaccinate with this vaccine.

(2) Vaccines Derived from Hamster Kidney Cell Cultures. Later on, a formalin inactivated vaccine was prepared from primary hamster kidney cell cultures in China which is under use since 1968. It is highly effective than any other vaccine [167] that shows an overall anti-viral efficacy between $76-95 \%$ in primary immunization of infants and provide wider protection. It is principle vaccine that had not been distributed outside of China. In last 45 years approximately 7 million doses of this JE vaccine (Beijing-3, P-3 strain) were administered to the patients per year up to 2005. Later on, formalin-inactivated vaccine was replaced by cell culturederived live attenuated vaccine [175] that showed very high efficacy against JE virus. It is a successful live vaccine which shows stable phenotypic and genetic characteristics and no reversion to neurovirulence of the vaccine strain and is unable to cause sucking mice or weanling mice disease [176, 177] (Table 2). It is under regular use for immunization of children.

(3) Chimeric Virus Vaccines. For achieving greatest protection Chimeric virus vaccines were developed by fusion of two viral proteins by making site directed mutations, specifically based on insertion of sequences which are responsible for virulence and pathogenesis. Therefore, to reconstruct Chimeri VaxJE and JE-VAX four major genotypes were identified by neutralization assays and passive protection studies in mice. However, greatest protection against JEV could be generated by using strains of genotypes II and III, although some protection was also afforded against genotypes IV strains and I. Chimeri Vax-JE vaccines were developed by UK/USA based company Acambis by growing on Vero cells. Further, attenuation of chimeric virus (YF-JE chimeric virus) was made by modifying at least three of the six amino acid in $\mathrm{E}$ protein [178], due to which it was assigned a name as Chimeri 
Vax-JETM. It elicits JEV neutralizing antibodies as well as protection against nasal and intracerebral virus challenge in rhesus monkeys $[13,14,179]$. It has shown superiority over JE-VAX [180] and provided real protection against Japanese encephalitis virus as it declines the pathological effects caused by JEV virus [178] in vaccination challenge protection assay in mice [181]. In addition, mouse brain derived vaccine is replaced by Japanese encephalitis chimeric virus vaccine (JECV) [176]. A single dose of JE-CV elicited rapid seroconversion in a higher proportion of vaccine than the current vaccines. In addition, mouse brain derived vaccine is replaced by Japanese encephalitis chimeric virus vaccine (JECV).

Similarly, another vaccine is under construction based on replication-defective canary poxvirus (ALVAC). It is highly attenuated vaccinia virus strain NYVAC and is used as vector to express the pr-M, E, NS1, and NS2a genes from JEV. The vaccine candidates were found to be well tolerated but their immunogenicity was too weak, especially in nonvaccinia immune volunteers, to warrant further development [14]. The vaccine was tested in human adult volunteers in the USA, where it showed good safety and immunogenicity. It has shown $94 \%$ efficacy in phase II trials and it raised protective neutralizing antibody levels after a single dose $[176,179]$. The Chimeric virus showed no replication in mosquitoes which were fed the Chimeri Vax-JE vaccine [182]. The vaccine is undergoing Phase III clinical trials in the USA and Australia for immunization $[183,184]$, whereas a parallel pediatric development program has been launched in Thailand by Sanofi Pasteur [185]. Recently Central Research Institute, Kasauli, has succeeded to develop a Japanese encephalitis vaccine by using mouse brain killed virus strain. Its 3 doses are required to generate immune protection in children against JEV (Table 2). Besides this, a tissue culture vaccine is also in developing phase and waiting for clinical trials for standardization and commercialization. In addition several other vaccines are in their later stage of development and are under trial $[161,165]$.

Mainly, safety of vaccine is assigned by using viremia, and clinical signs and neuropathological changes occur in patients. It is also determined by immune response generated by vaccines and protection developed against virus challenge. Further, postvaccination effects such as reactinogenicity and persistence of immune response are also considered for evaluation. However, it is true for a good vaccine as it shows a moderate to severe hypersensitivity type reactions, mainly neurological adverse effects in patients. There is no reduction in seroconversion rates when other childhood vaccines are given simultaneously. In addition, vaccine administration in patients shows local and systemic side effects like urticaria and angioedema (1 case per 1000 vaccines) [170]. Therefore, for improving the efficiency of flavivirus vaccines and its adverse effects molecularly mixed vaccines are designed and prepared. These are recognized as second generation vaccines.

3.2.3. Second Generation JE Vaccines. Second generation vaccines are nonmouse brain derived JE vaccines developed by using genetically engineered virus proteins. These are based on promising approach and are considered to be the best JE vaccines of the future [186]. A live attenuated genetically engineered (Chimeri Vax JE vaccine) virus was made by replacing the genes encoding the two structural proteins (prM and E) of yellow fever virus (YF), 17D vaccine strain with corresponding genes of an attenuated vaccine strain (SA14-2-14) of JE virus [2, 187]. For this purpose, molecular clones of YFV (yellow fever virus) and Japanese encephalitis virus were used and molecular basis of neurovirulence in mouse model was established before going for vaccination trials. Six amino acid changes were made in $\mathrm{E}$ protein (E107, E138, E176, E279, E315, and E439), and three in the nonstructural genes were associated with the attenuation [188]. Thus, both nonstructural protein prM and E protein contain antigens conferring protective humoral and cellular immunity against JEV. It is a safer and cheaper vaccine, which has demonstrated $88-96 \%$ effectiveness in the largescale trials. Vaccine showed systemic reactiongenicity and no neurotoxicity. This vaccine was administered in children in Nepal where it showed $96 \%$ efficacy. It is licensed for use in Nepal, SriLanka, and China.

Similarly another Chimeri Vax JE or IMOJEV was prepared, tested, and under licensing stage in Australia [189]. It is prepared by using SA14-14-2 JEV strain and its eight passages were done in primary kidney cells of dog, cultivated in Vero cells, and formulated with $0.1 \%$ aluminium hydroxide. Vero cells maintained in serum free medium are used as main substrate of this vaccine [190]. This vaccine is under trail and its 2 doses of 6 microgram each is used for safe vaccination of children [191]. It has shown very high seroconversion rate and shows better safety in mice and nonhuman primates after immunization [192]. In man, it provides better preclinical safety, immunogenicity, and protective efficacy than any other vaccine. Further, Biken strain based vaccine named as JE-Vax was developed in United States [193] and is widely used in western countries. Further, IXIARO or IC51 vaccine was developed by Austrian Biotech Company Intercell Biomedical Ltd. It requires only 2 doses for complete immunization, and is currently licensed in the USA, Europe, UK, Canada, and Australia. [194]. It was prepared by using purified formalin inactivated whole virus $[169,195,196]$. Its two trials have been completed and licensed by the US FDA for adults [184] (US-FDA).

Both XIARO-IC51 and SA 13-14-2 JE vaccines have different seroconversion rates and neutralizing antibody titers. Further, a Vero a cell derived purified inactivated JE vaccine was developed by Chengdu Institute of Biological Products in China in 1988 [197]. Later on it was made by several other manufacturers [164], either by using the virulent Nakayama strain or by attenuated SA14-14-2 JEV strain [197, 198]. It is a live attenuated vaccine which is produced by using a stable neuro-attenuated strain of the JE virus (SA-14-14-2) and is licensed in China and several Asian countries. It was extensively used in India from 2006 to 2008 for immunization of children [199]. It was prepared after 11 passages done in weaning mice followed by 100 passages in primary hamster kidney cells [200], lyophilized, and administered to children at one year of age and again at two years [201]. Although this vaccine is not WHO prequalified at this time, still efforts 
are being made to bring the production and quality control to international standards. First time, it was administered in 200000 children southern China where it showed 99-100\% seroconversion rate in nonimmune subjects and provided protective efficacy over 5 years [202]. Its single dose can stimulate adequate immune response in the recipient of the vaccine [203], and gave $96.2 \%$ efficacy [200]. Its postvaccination studies showed $90 \%$ neutralizing antibody persistence at 4 years and $64 \%$ at 5 years after a single dose of the vaccine $[176,198,204,205]$. In present time, more than 30 million doses of the live SA14-2-14 vaccine are distributed annually in southern and western China. In India from May 2006 it was administered in 9.3 million children in 11 districts scattered among 4 states where JE was considered as highly endemic [165]. After vaccination few adverse events with severe symptoms and mortalities were also reported, but most of the immunized cases were found survived [162]. Later on Green Cross vaccine was developed by Green Cross vaccine company, but it was not licensed in the United Kingdom. Similarly, a Semple vaccine from phenolized sheep brain was developed in Thailand and is used for vaccination of children aged between 1-6 years [206]. It spectrally reduced the rate of neurological complications in patients up to 8.31 cases per 1000 persons vaccinated $(1: 120)$ and successfully reduced the number of susceptible children after the second dose [207]. Generally, 3 doses of this vaccine are prescribed for immunization and third dose is given at 6-month interval after second dose [208]. However, for protection from JEV infection both inactivated and the attenuated vaccines were used for immunization purpose. More often, only two types of JE vaccines XIARO-IC51 and SA 13-14-2 are currently in use in several JE endemic countries within the Asia-Pacific region. These are internationally available and W.H.O recognized vaccines, which have cut down cumulative attacking rate of encephalitis up to 51 per 100,000 in the placebo group and 5 per 100,000 in each vaccine group. The development of a Swine vaccine against JEV is on high priority as it could help to prevent epidemics in humans (Table 2). Similarly, both LAV SA-14-14-2 virus and inactivated $\mathrm{P}_{3}$ strain (IPV) vaccine showed protective efficacy against JEV genotype I.

\subsubsection{Third Generation Vaccines}

DNA Vaccines. To fight against flavivirus infection DNA vaccines are generated by using virus DNA encoding antigenic proteins; the recipients take up the DNA and encoded protein antigen is expressed leading to both humoral and cell mediated immune responses. DNA integrates into the chromosomal DNA and viral antigen is expressed in the injection area. DNA vaccines have more advantage as encoded protein is expressed in the host in its natural form and there occurs no destruction or modification. The immune response is accurately directed to the antigen exactly as it is expired by the pathogen. DNA vaccines show prolonged expression of the antigen, which generates specific immunological memory. These have more advantage over peptide antigens as they do not require handling and storage of the plasmid DNA. As it is well known fact that natural infection also generates immunity but DNA vaccines much ably generate immunity much faster and initiate strong immune response upon administration [78]. However, plasmid based DNA immunization provides titer 1:600, while formalininactivated vaccine provides $1: 1000$ [209]. Besides this, oral immunization of mice with live JEV virus also generates a protective immune response [210].

Peptide Vaccine. Most of the present day vaccines are prepared from an attenuated pathogen or from inactivated diseasecausing organisms or a suitable part of it for example a toxin. However, often the antigen to which the immune system responds is a relatively small number of amino acids or peptides. Therefore, for production of antibodies either complete viral protein or its formed peptides having small segments of proteins or antigenic determinants or epitopes are used to elicit the immune response [211]. These were found noninfectious after use in comparison to DNA vaccine. Therefore, multipurpose peptide with several different epitopes can be generated for production of high titers of JEV neutralizing antibodies. However, for active immunization, many natural and recombinant peptides have been used to generate potential vaccines. A Chimeric T helper B-cell peptide vaccine for Japanese encephalitis virus was indigeniously developed in 2008 by Indian Scientists at National Institute of Virology, Pune, by M. M. Gore and his team and got a U.S Patent [212]. Peptide vaccines are safe, easy to store, and can be carried to tropical regions for immunization by storing them in sealed dry ice packets. There are few demerits of peptide vaccines as they show poor immunogenicity because short amino acid sequences are not highly immunogenic, and fruitful changes are not possible in the peptide molecule to elicit an immune response. Furthermore, peptides mainly synthetic require mixing of large amount of adjuvant, which is considered much undesirable and unsafe. Further, chemical conjugation of peptides is a very difficult task. If prepared these are not much reproducible because chances of linker peptide after conjugation may remain immunogenic are un-ensured. Peptide vaccines are devoid of any T-cell epitopes and amino acid sequences do not show immune suppression, molecular-mimicry-like DNA sequences. DNA vaccines enhance infection induced antibody responses differently. Maximum neutralization titer $1: 20$ of a peptide vaccine found effective against JEV [134], while it is much higher in case of DNA vaccines.

Though peptide vaccines are easy to develop, these are temperature sensitive and denatured at normal temperature and are of no use. Furthermore, stability of single chain proteins could be optimized by using new linker molecules [213] or by generating more appropriate short antigen epitopes with defined well structure and function to elicit strong antigenicity [214]. However, rod shaped virus particles (VLPs) were made by assembling the JGMV and CV peptides and are used to raise antibodies or vaccines [134]. However, before preparing a peptide vaccine it is very essential to identify the peptide sequences that trigger a protective immune response. Besides this use of noninfection, subviral extracellular particle (EPs) is an inexpensive and safety strategy for the production of protein based flavivirus vaccines. There is a 


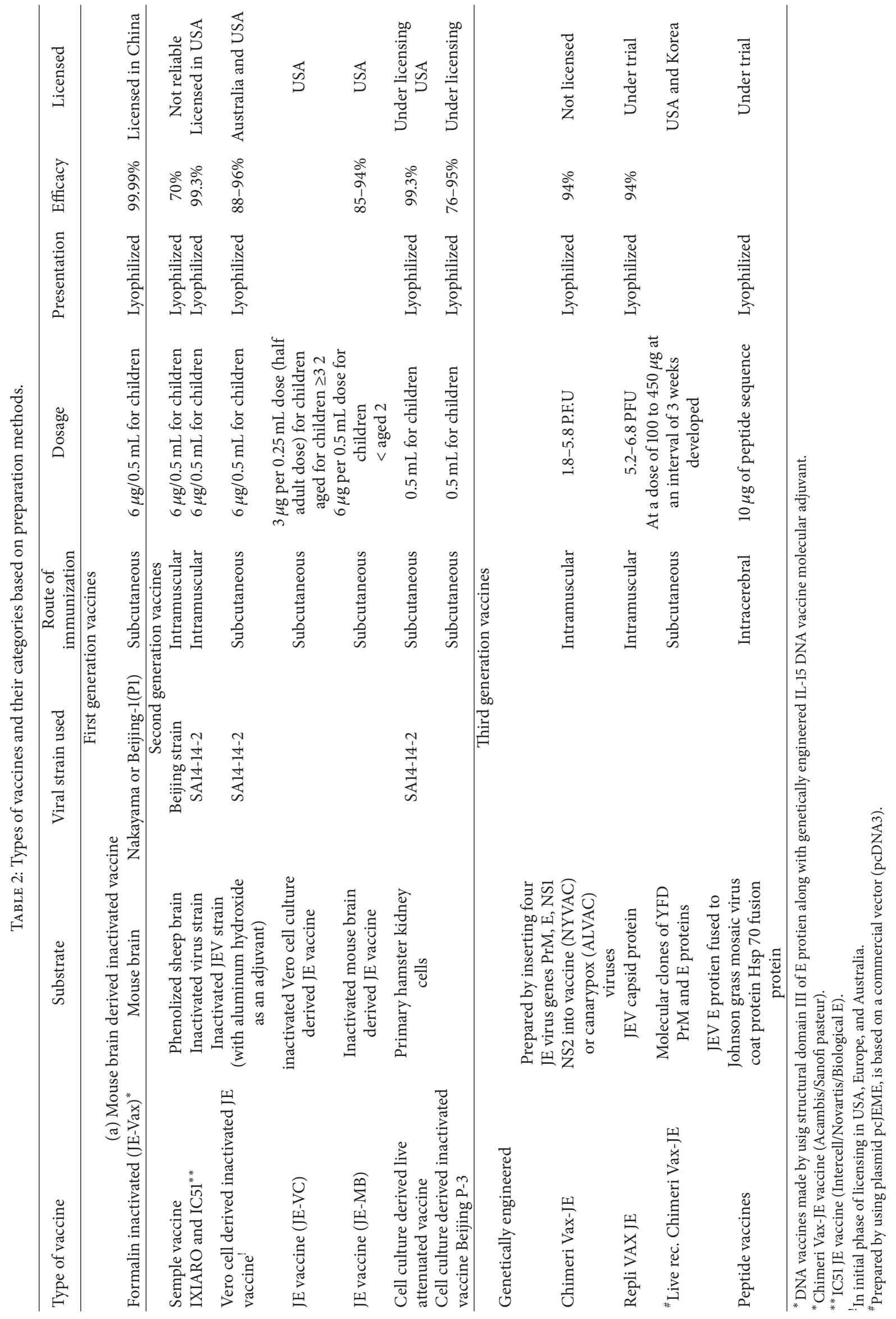


possibility that peptides derived from E protein may have better possibilities to generate VLPs and fusion proteins (JGMV peptide) which can be used to obtain higher titers of neutralizing antibodies. However, for production of prM and envelop E protein mammalian cells are used to yield more amount of these proteins. Recently, insect cell expression system with $\mathrm{Sf}_{9}$ cells to generate viral antigens such as JEV envelops proteins. These cells could produce 10-100-fold larger amount of envelop proteins than mammalian cells [215]. Besides this, simple feed batch cultivation of recombinant $E$. coli cells resulted in high yield of recombinant JE virus proteins [216]. These multivalent subunit peptide vaccines showed better cellular and humoral immunity rather than simple vaccines. These are also developed by constructing synthetic peptides that may contain both immunodominant $\mathrm{B}$ cells and T-cell epitopes. To generate an appropriate and desirable CTL response, the vaccine must be developed intracellularly so that the peptides can be processed and presented together with class I MHC molecules. These can be developed by preparing solid matrix antibody antigen complexes by attaching monoclonal antibodies to particulate solid matrices. Besides this, immunostimulating complexes of liposome having membrane proteins from many pathogens are developed for immunization purposes.

However, for better treatment only more stable vaccines/ antibodies are to be provided for generation of longterm immunity in undiseased population. Based on recent vaccination events and successes obtained, no doubt an effective vaccination can curb the JEV generated disease and pathogenesis in millions of patients [169]. Vaccination is the only tool that can successfully stop and eliminate the JE disease. It is only effective method for sustainable control of JEV infection in rural and suburban areas. Further, to break its annual occurrence and continuous spreading mosquito control is highly essential. However, it seems to be very difficult to control JEV transmission vector (Culex sp.) in breeding paddy field or in any other small habitat because of pesticide generated toxicity, resistance, and host range differences. Hence, both vaccination and mosquito control are most essential strategies for the prevention of JE disease. But vaccination of infants and children of various age groups enhances immunity level and provides extra safe cover for their survivorship after vaccination. However, for generation of anti-viral defense against JE virus, active vaccination provides strong protective immunity.

Furthermore, virus-specific chemotherapy could also manage inhibition of virus replication that may result in inhibition of infection at an earlier stage. Similarly, DNA enzymes inhibit the replication and proliferation of Japanese encephalitis virus [217] and result in a sharp reduction in JEV titer in host brain, which may lead to an extended lifespan or recovery of infected patient. Further, diverse mimmotopes of active antigens that can mimic the JEV neutralizing antigen activity can be generated. Furthermore, so many JEV infectious mutant clones can be generated by insertion of short introns or cloning into artificial chromosomal systems [218]. Further, nitric oxide (NO) has been shown to suppress Japanese encephalitis virus (JEV) RNA synthesis, viral protein accumulation, and virus release from infected cells $[219,220]$. Use of various types of cytokines, complement proteins, enzymes, antibodies, and passive transfer of activated CTLs, T cells, B cells, and NK cells can be used to destruct viral infection. In addition, more stress must be given on interventions like mosquito control, and avoidance of human exposure to mosquitoes and reservoir hosts can make successful control of JE disease. In addition, other strategies like RNA silencing and interference, activation of complement, DNA enzymes also potentially work against JE virus generated infection. Further, mimotopes of virus antigens, VLPs, and fusion proteins are also used for generation of potential vaccines.

\section{Conclusion}

Viruses use series of molecules to make inhibitory responses for establishing infection inside human host. However, in response to a virus attack, wide ranges of innate immune mechanisms operate to eliminate the virus invasion, but fast increase in virus population and repeated exposure of viral proteins exacerbate pathogenesis. In addition, virus avoids recognition and its elimination from a sequestered defense made by body cells and molecules in operation. With this, there occurs an increase in virus-infected cells, due to immune deprivation and sharp decrease in soluble factors. Other defense mechanisms, which are operated, involve the acute phase proteins such as C-reactive proteins that help in anti-inflammatory response against virus infection. However, more interesting is the defense developed by viruses against anti-infective agents, cells, and molecules. Hence, study of flavivirus evasion is very important to know the natural history of virus and its infectivity in different hosts mainly in different animal models.

JEV is an RNA virus that has larger chances of integration of viral genes into the host genome. It will lead to enhance the viral infectivity inside host, and virus can nullify the effect of innate and humoral immune responses easily. Further, there are chances of generation of new JEV strains because of mutations that occurred in local genotypes due to reversions, deletions or addition, or position shifts of sequences in virus genome. It may generate highly infective gene products/ proteins that will increase the spectrum of disease incidences, neuropathogenesis, and lethality. Interestingly, other highly pathogenic long-term viruses are also available in the same environment, hence easy transmission and infectivity potential may differ from host to host transfer. It will make viruses more aware about all possible alterations occurred in nonhost or a potential host (immunized) genome after which viruses may do necessary changes accordingly. However, due to their short genome, chances of assimilation of new sequences from other viruses are lesser and lesser. But chances of increase in copy number of harmful signaling molecules cannot be declined. Viruses may adopt all these changes accordingly or make themselves more resistant to any drug or any vaccine, because such type of transfer may lead to an increase in antigenicity that may result in high genetic load for carrying new harmful genes causing severe neuropathogenesis. There is no answer to crossreactivity of virulence determinants of envelope proteins and 
vaccine induced Pathogenesis. Further, mixed Population structure shows presence of different viruses with variable antigens and different incubation periods. Either in such a condition, attainment of new genes by viruses may increase or decrease the spectrum of invasion, pathogenesis and lethality cannot be answered exactly. But in such conditions, incubation period will affect immune responses and antiviral defense. Possibly it may increase the chances to avoid innate immune responses or to make CTL activity delayed in the host. However, in future strains of flaviviruses, alternate methods of survival may limit their detection by soluble and cellular mediator molecules by developing an error prone new enzyme system. Antigens with new epitopes with complex structure or modified viral proteins will also create problem not only in recognition by antibody molecules and $\mathrm{T}$ cells to maintain natural immunity of host but also inhibit the action of potential vaccines. It might slow down or suppress the action of interferons, complement proteins or generate a new cascade of molecules to block CTL activity. Chances are also possible that viruses at some stage may foil the RNA interference or suppress this vary mechanism. Therefore, it is highly investigative to explore the nature and pathogenesis made by other viruses, which possess similar disease spectrum. Alternatively these critical modifications in immune responses to new virus inhibitors could be identified in in vitro cell culture studies as well as in animal models, but due to short life span, chances to drag out hard facts are very less. Hence, characterization of viral proteins/factors is highly essential to clarify their responsible role in evasive mechanisms. Such explorations could provide some better tools in pharmacology to design novel therapeutic molecules, mainly to generate newer vaccines with high antiviral efficacy not only against JEV but also against the entire family of flaviviruses.

Further, vaccination should be made an essential part for rural people in areas of an endemic region during the transmission season. In addition, for progressive and safer vaccination a vaccine should be W.H.O. prequalified and show the production and quality control of international standards. Before immunization a vaccine should be well tested and passed through clinical trials for standardization and commercialization. It must be essentially tested for neurovirulence in JE susceptible laboratory animals for its postvaccination adverse effects. Such trials may be helpful to find distinction between a virulent or nonvirulent strain. Even after having excellent tolerability, a vaccine should be tested to confirm allergic reactions in patients. Vaccines with poor immunogenicity must be avoided for administration because these cannot elicit an effective immune response to subside the viral infection. Though maximum duration of vaccines or antibody protection cannot be decided exactly, but persistence of post vaccination neutralizing antibody in the circulation can be measured. It will help in maintaining better protection. Both immunization vaccine dose and boosters recommended for people are to be determined. Further, for improving the efficiency of flavivirus vaccines molecularly mixed vaccines or multivalent fusion peptides are to be designed to be used for immunization and to achieve long-term immune protection against JEV. Further, intratypic viruses with appropriate mutations can be generated by site directed mutagenesis, to enhance potential of DNA or protein vaccines. For this purpose, single site mutations can be generated in structural proteins in domain or in terminal anchor region, with-cluster specific functionality and multiple neurovirulence determinants to generate vaccines of high potential. It will open up the possibility of using such molecules for treating patients with JE by inhibiting viral immune attack and its replication in the brain. In fact, VLPs or peptides will be proved more protective. Hence, for elimination of infectious viruses thorough understanding of viral antigens, their modifications is to be required to generate more appropriate and highly successful vaccine/s. Further, occurrence of climate induced genotypic variations or mutations and other molecular changes that occurred in flavaiviruses must be identified, inexcusably added, and considered for generating new potential vaccines.

Further, antigenic profiling of all JE virus and associating strains must be known to explore the vary reasons of severity of epidemics. Further, time bound consistent powerful surveillance of JEV in endemic areas will provide a real-time data on its infectivity, morbidity, mortality, and clinical care of patients. It will provide a better safe guard to pediatric groups, as proper JEV diagnosis will help in maintaining strong preventive and therapeutic measures. For fast action and finding good outcomes, JEV diagnostic laboratories must be established in endemic areas for timely diagnosis of JE virus to avoid extra delay in treatment. It will certainly cut down mortality rate in infants. Further, neurovirulence generated in JE vaccinated population with high documented immunity and nonvaccinated patients should be undertaken in endemic areas to assess how frequently JE virus/ flaviviruses is/are surviving in existing environmental conditions and its possible risks in future. Most significant is to achieve absolute safety against JE virus for which surveillance, immunization and vector control are highly essential.

\section{Abbreviations}

JEV: Japanese encephalitis virus

TCR: T-cell receptor

CTL: Cytotoxic lymphocytes

NCPs: Neural progenitor cells

CNS: Central nervous system

WNV: West Nile virus

TBEV: Tick-borne encephalitis virus.

\section{References}

[1] T. P. Endy and A. Nisalak, "Japanese encephalitis virus: ecology and epidemiology," Current Topics in Microbiology and Immunology, vol. 267, pp. 11-48, 2002.

[2] M. Gromeier, E. Wimmer, and A. E. Gorbalenya, "Genetics, pathogenesis and evolution of picornaviruses," in Origin and Evolution of Viruses, E. Domingo, R. G. Webster, and J. J. Holland, Eds., pp. 287-343, Academic Press, London, UK, 1999.

[3] T. J. Chambers, C. S. Hahn, R. Galler, and C. M. Rice, "Flavivirus genome organization, expression, and replication," Annual Review of Microbiology, vol. 44, pp. 649-688, 1990. 
[4] C. Lin, S. M. Amberg, T. J. Chambers, and C. M. Rice, "Cleavage at a novel site in the NS4A region by the yellow fever virus NS2B-3 proteinase is a prerequisite for processing at the downstream 4A/4B signalase site," Journal of Virology, vol. 67, no. 4, pp. 2327-2335, 1993.

[5] C. M. Rice, E. M. Lenches, S. R. Eddy, S. J. Shin, R. L. Sheets, and J. H. Strauss, "Nucleotide sequence of yellow fever virus: implications for flavivirus gene expression and evolution," Science, vol. 229, no. 4715, pp. 726-733, 1985.

[6] C. M. Rice, E. G. Strauss, and J. H. Strauss, "Structure of the flavivirus genome," in The Togaviridae and Flaviviridae, S. Schlesinger and M. J. Schlesinger, Eds., pp. 279-326, Plenum Press, New York, NY, USA, 1986.

[7] H. Sumiyoshi, C. Mori, I. Fuke et al., "Complete nucleotide sequence of the Japanese encephalitis virus genome RNA," Virology, vol. 161, no. 2, pp. 497-510, 1987.

[8] T. Yamashita, H. Unno, Y. Mori et al., "Crystal structure of the catalytic domain of Japanese encephalitis virus NS3 helicase/nucleoside triphosphatase at a resolution of $1.8 \AA$," Virology, vol. 373, no. 2, pp. 426-436, 2008.

[9] Y. Q. Deng, J. X. Dai, G. H. Ji et al., "A broadly flavivirus cross-neutralizing monoclonal antibody that recognizes a novel epitope within the fusion loop of e protein," PLoS ONE, vol. 6, no. 1, Article ID e16059, 2011.

[10] F. X. Heinz, R. Berger, W. Tuma, and C. Kunz, "A topological and functional model of epitopes on the structural glycoprotein of tick-borne encephalitis virus defined by monoclonal antibodies," Virology, vol. 126, no. 2, pp. 525-537, 1983.

[11] E. A. Gould, A. Buckley, A. D. T. Barrett, and N. Cammack, "Neutralizing (54K) and non-neutralizing (54K and 48K) monoclonal antibodies against structural and non-structural yellow fever virus proteins confer immunity in mice," Journal of General Virology, vol. 67, no. 3, pp. 591-595, 1986.

[12] M. W. Brandriss, J. J. Schlesinger, E. E. Walsh, and M. Briselli, "Lethal 17D yellow fever encephalitis in mice. I. Passive protection by monoclonal antibodies to the envelope proteins of $17 \mathrm{D}$ yellow fever and dengue 2 viruses," Journal of General Virology, vol. 67, no. 2, pp. 229-234, 1986.

[13] M. Bray, B. T. Zhao, L. Markoff, K. H. Eckels, R. M. Chanock, and C. J. Lai, "Mice immunized with recombinant vaccinia virus expressing dengue 4 virus structural proteins with or without nonstructural protein NS1 are protected against fatal dengue virus encephalitis," Journal of Virology, vol. 63, no. 6, pp. 28532856, 1989.

[14] Y. L. Lin, L. K. Chen, C. L. Liao et al., "DNA immunization with Japanese encephalitis virus nonstructural protein NS1 elicits protective immunity in mice," Journal of Virology, vol. 72, no. 1, pp. 191-200, 1998.

[15] E. Konishi, S. Pincus, B. A. L. Fonseca, R. E. Shope, E. Paoletti, and P. W. Mason, "Comparison of protective immunity elicited by recombinant vaccinia viruses that synthesize E or NS1 of Japanese encephalitis virus," Virology, vol. 185, no. 1, pp. 401$410,1991$.

[16] J. J. Schlesinger, M. W. Brandriss, and E. E. Walsh, "Protection against 17D yellow fever encephalitis in mice by passive transfer of monoclonal antibodies to the nonstructural glycoprotein gp48 and by active immunization with gp48," Journal of Immunology, vol. 135, no. 4, pp. 2805-2809, 1985.

[17] J. J. Schlesinger, M. W. Brandriss, C. B. Cropp, and T. P. Monath, "Protection against yellow fever in monkeys by immunization with yellow fever virus nonstructural protein NS1," Journal of Virology, vol. 60, no. 3, pp. 1153-1155, 1986.
[18] H. Kawano, V. Rostapshov, L. Rosen, and C. J. Lai, "Genetic determinants of dengue type 4 virus neurovirulence for mice," Journal of Virology, vol. 67, no. 11, pp. 6567-6575, 1993.

[19] M. Bray and C. J. Lai, "Construction of intertypic chimeric dengue viruses by substitution of structural protein genes," Proceedings of the National Academy of Sciences of the United States of America, vol. 88, no. 22, pp. 10342-10346, 1991.

[20] L. J. Johnston, G. M. Halliday, and N. J. King, "Langerhans cells are targets of dengue virus infection," Nature Medicine, vol. 6, no. 7, pp. 816-820, 2000.

[21] Y. Zhang, P. Chen, R. Cao, and J. Gu, "Mutation of putative $\mathrm{N}$-Linked glycosylation sites in japanese encephalitis virus premembrane and envelope proteins enhances humoral immunity in BALB/C mice after DNA vaccination," Virology Journal, vol. 8, article 138, 2011.

[22] L. K. Chen, C. L. Liao, C. G. Lin et al., "Persistence of Japanese encephalitis virus is associated with abnormal expression of the nonstructural protein NS1 in host cells," Virology, vol. 217, no. 1, pp. 220-229, 1996.

[23] J. J. Hung, M. T. Hsieh, M. J. Young, C. L. Kao, C. C. King, and W. Chang, "An external loop region of domain III of dengue virus type 2 envelope protein is involved in serotype-specific binding to mosquito but not mammalian cells," Journal of Virology, vol. 78, no. 1, pp. 378-388, 2004.

[24] A. Goto, K. Yoshii, M. Obara et al., "Role of the N-linked glycans of the prM and $\mathrm{E}$ envelope proteins in tick-borne encephalitis virus particle secretion," Vaccine, vol. 23, no. 23, pp. 3043-3052, 2005.

[25] H. Y. Wei, L. F. Jiang, D. Y. Fang, and H. Y. Guo, “Dengue virus type 2 infects human endothelial cells through binding of the viral envelope glycoprotein to cell surface polypeptides," Journal of General Virology, vol. 84, no. 11, pp. 3095-3098, 2003.

[26] J. M. Kim, S. I. Yun, B. H. Song et al., "A single N-linked glycosylation site in the Japanese encephalitis virus prM protein is critical for cell type-specific prM protein biogenesis, virus particle release, and pathogenicity in mice," Journal of Virology, vol. 82, no. 16, pp. 7846-7862, 2008.

[27] M. Gromeier, B. Bossert, M. Arita, A. Nomoto, and E. Wimmer, "Dual stem loops within the poliovirus internal ribosomal entry site control neurovirulence," Journal of Virology, vol. 73, no. 2, pp. 958-964, 1999.

[28] S. B. Zhang, P. Li, and X. Z. Liu, "Analysis on neutralization antibody titer of Japanese B encephalitis virus in healthy population in Shaanxi province," Zhongguo Yi, Miao He Mian Yi, vol. 16, no. 3, pp. 251-257, 2010.

[29] M. Zhang, B. Gaschen, W. Blay et al., "Tracking global patterns of N-linked glycosylation site variation in highly variable viral glycoproteins: HIV, SIV, and HCV envelopes and influenza hemagglutinin," Glycobiology, vol. 14, no. 12, pp. 1229-1246, 2004.

[30] A. Goffard, N. Callens, B. Bartosch et al., "Role of N-linked glycans in the functions of hepatitis $\mathrm{C}$ virus envelope glycoproteins," Journal of Virology, vol. 79, no. 13, pp. 8400-8409, 2005.

[31] R. W. Schlesinger, "Virus-host interactions in natural and experimental infections with alphaviruses and flaviviruses," in The Togaviruses, R. W. Schlesinger, Ed., pp. 83-104, Academic Press, New York, NY, USA, 1980.

[32] V. I. Agol, S. G. Drozdov, V. P. Grachev et al., "Recombinants between attenuated and virulent strains of poliovirus type 1 : derivation and characterization of recombinants with centrally located crossover points," Virology, vol. 143, no. 2, pp. 467-477, 1985. 
[33] T. Omata, M. Kohara, S. Kuge et al., "Genetic analysis of the attenuation phenotype of poliovirus type 1," Journal of Virology, vol. 58, no. 2, pp. 348-358, 1986.

[34] M. Tardy-Panit, B. Blondel, A. Martin, F. Tekaia, F. Horaud, and F. Delpeyroux, "A mutation in the RNA polymerase of poliovirus type 1 contributes to attenuation in mice," Journal of Virology, vol. 67, no. 8, pp. 4630-4638, 1993.

[35] T. P. Monath, J. Arroyo, I. Levenbook et al., "Single mutation in the flavivirus envelope protein hinge region increases neurovirulence for mice and monkeys but decreases viscerotropism for monkeys: relevance to development and safety testing of live, attenuated vaccines," Journal of Virology, vol. 76, no. 4, pp. 19321943, 2002.

[36] M. Ahmed, T. R. Marino, S. Puckett, N. D. Kock, and D. S. Lyles, "Immune response in the absence of neurovirulence in mice infected with M protein mutant vesicular stomatitis virus," Journal of Virology, vol. 82, no. 18, pp. 9273-9277, 2008.

[37] J. J. Schlesinger, S. Chapman, A. Nestorowicz, C. M. Rice, T. E. Ginocchio, and T. J. Chambers, "Replication of yellow fever virus in the mouse central nervous system : comparison of neuroadapted and non-neuroadapted virus and partial sequence analysis of the neuroadapted strain," Journal of General Virology, vol. 77, no. 6, pp. 1277-1285, 1996.

[38] R. Feuer, I. Mena, R. R. Pagarigan, S. Harkins, D. E. Hassett, and J. L. Whitton, "Coxsackievirus B3 and the neonatal CNS: the roles of stem cells, developing neurons, and apoptosis in infection, viral dissemination, and disease," American Journal of Pathology, vol. 163, no. 4, pp. 1379-1393, 2003.

[39] R. Feuer, R. R. Pagarigan, S. Harkins, F. Liu, I. P. Hunziker, and J. L. Whitton, "Coxsackievirus targets proliferating neuronal progenitor cells in the neonatal CNS," Journal of Neuroscience, vol. 25, no. 9, pp. 2434-2444, 2005.

[40] I. Kosugi, Y. Shinmura, H. Kawasaki et al., "Cytomegalovirus infection of the central nervous system stem cells from mouse embryo: a model for developmental brain disorders induced by cytomegalovirus," Laboratory Investigation, vol. 80, no. 9, pp. 1373-1383, 2000.

[41] S. Das and A. Basu, "Inflammation: a new candidate in modulating adult neurogenesis," Journal of Neuroscience Research, vol. 86, no. 6, pp. 1199-1208, 2008.

[42] K. S. A. Myint, R. V. Gibbons, G. C. Perng, and T. Solomon, "Unravelling the neuropathogenesis of Japanese encephalitis," Transactions of the Royal Society of Tropical Medicine and Hygiene, vol. 101, no. 10, pp. 955-956, 2007.

[43] S. L. Hills and D. C. Phillips, "Past, present, and future of Japanese encephalitis," Emerging Infectious Diseases, vol. 15, no. $1,2009$.

[44] M. Oglesbee and S. Niewiesk, "Measles virus neurovirulence and host immunity," Future Virology, vol. 6, no. 1, pp. 85-99, 2011.

[45] A. Ghoshal, S. Das, S. Ghosh et al., "Proinflammatory mediators released by activated microglia induces neuronal death in Japanese encephalitis," GLIA, vol. 55, no. 5, pp. 483-496, 2007.

[46] V. Swarup, S. Das, S. Ghosh, and A. Basu, "Tumor necrosis factor receptor-1-induced neuronal death by TRADD contributes to the pathogenesis of Japanese encephalitis," Journal of Neurochemistry, vol. 103, no. 2, pp. 771-783, 2007.

[47] T. Solomon, H. Ni, D. W. C. Beasley, M. Ekkelenkamp, M. J. Cardosa, and A. D. T. Barrett, "Origin and evolution of Japanese encephalitis virus in Southeast Asia," Journal of Virology, vol. 77, no. 5, pp. 3091-3098, 2003.
[48] K. D. Yang, W. T. Yeh, R. F. Chen et al., "A model to study neurotropism and persistency of Japanese encephalitis virus infection in human neuroblastoma cells and leukocytes," Journal of General Virology, vol. 85, no. 3, pp. 635-642, 2004.

[49] K. Yasui, "Neuropathogenesis of Japanese encephalitis virus," Journal of NeuroVirology, vol. 8, supplement 2, pp. 112-114, 2002.

[50] D. N. Abrous, M. Koehl, and M. Le Moal, "Adult neurogenesis: from precursors to network and physiology," Physiological Reviews, vol. 85, no. 2, pp. 523-569, 2005.

[51] P. M. Lledo, M. Alonso, and M. S. Grubb, "Adult neurogenesis and functional plasticity in neuronal circuits," Nature Reviews Neuroscience, vol. 7, no. 3, pp. 179-193, 2006.

[52] D. M. P. Lawrence, L. C. Durham, L. Schwartz, P. Seth, D. Maric, and E. O. Major, "Human immunodeficiency virus type 1 infection of human brain-derived progenitor cells," Journal of Virology, vol. 78, no. 14, pp. 7319-7328, 2004.

[53] M. D. Krathwohl and J. L. Kaiser, "HIV-1 promotes quiescence in human neural progenitor cells," The Journal of Infectious Diseases, vol. 190, pp. 216-226, 2004.

[54] M. S. Diamond, B. Shrestha, A. Marri, D. Mahan, and M. Engle, "B cells and antibody play critical roles in the immediate defense of disseminated infection by West Nile encephalitis virus," Journal of Virology, vol. 77, no. 4, pp. 2578-2586, 2003.

[55] N. S. Zeidner, S. Higgs, C. M. Happ, B. J. Beaty, and B. R. Miller, "Mosquito feeding modulates Th1 and Th2 cytokines in flavivirus susceptible mice: an effect mimicked by injection of sialokinins, but not demonstrated in flavivirus resistant mice," Parasite Immunology, vol. 21, no. 1, pp. 35-44, 1999.

[56] S. J. L. Wu, G. Grouard-Vogel, W. Sun et al., "Human skin Langerhans cells are targets of dengue virus infection," Nature Medicine, vol. 6, no. 7, pp. 816-820, 2000.

[57] A. F. Ochsenbein and R. M. Zinkernagel, "Natural antibodies and complement link innate and acquired immunity," Immunology Today, vol. 21, no. 12, pp. 624-630, 2000.

[58] J. E. Volanakis, "The role of complement in innate and adaptive immunity," Current Topics in Microbiology and Immunology, vol. 266, pp. 41-56, 2002.

[59] X. J. Da Costa, M. A. Brockman, E. Alicot et al., "Humoral response to herpes simplex virus is complement-dependent," Proceedings of the National Academy of Sciences of the United States of America, vol. 96, pp. 708-712, 1999.

[60] M. W. Douglas, A. M. Kesson, and J. C. King, "CTL recognition of West Nile virus-infected fibroblasts is cell cycle dependent and is associated with virus-induced increases in class I MHC antigen expression," Immunology, vol. 82, no. 4, pp. 561-570, 1994.

[61] A. M. Kesson, R. V. Blanden, and A. Mullbacher, "The primary in vivo murine cytotoxic $\mathrm{T}$ cell response to the flavivirus, West Nile," Journal of General Virology, vol. 68, no. 7, pp. 2001-2006, 1987.

[62] A. B. Kulkarni, A. Mullbacher, and R. V. Blanden, "In vitro Tcell proliferative response to the flavivirus, West Nile," Viral Immunology, vol. 4, no. 2, pp. 73-82, 1991.

[63] I. Kurane and F. A. Ennis, "Cytotoxic T lymphocytes in dengue virus infection," Current Topics in Microbiology and Immunology, vol. 189, pp. 93-108, 1994.

[64] I. Kurane, B. L. Innis, C. H. Hoke Jr. et al., "T cell activation in vivo by dengue virus infection," Journal of clinical \& laboratory immunology, vol. 46, no. 1, pp. 35-40, 1995.

[65] I. Kurane, B. L. Innis, A. Nisalak et al., "Human T cell response to dengue virus antigens. Proliferative responses and interferon 
gamma production," The Journal of Clinical Investigation, vol. 83, no. 2, pp. 506-513, 1989.

[66] K. Murali-Krishna, V. Ravi, and R. Manjunath, "Protection of adult but not newborn mice against lethal intracerebral challenge with Japanese encephalitis virus by adoptively transferred virus-specific cytotoxic T lymphocytes: requirement for L3T4+ T cells," Journal of General Virology, vol. 77, no. 4, pp. 705-714, 1996.

[67] K. Takada, H. Masaki, E. Konishi, M. Takahashi, and I. Kurane, "Definition of an epitope on Japanese encephalitis virus (JEV) envelope protein recognized by JEV-specific murine CD8+ cytotoxic T lymphocytes," Archives of Virology, vol. 145, no. 3, pp. 523-534, 2000.

[68] N. Nathanson and G. A. Cole, "Fatal Japanese encephalitis virus infection in immunosuppresed spider monkeys," Clinical and Experimental Immunology, vol. 6, no. 1, pp. 161-166, 1970.

[69] N. Nathanson and G. A. Cole, "Immunosuppression and experimental virus infection of the nervous system," Advances in Virus Research, vol. 16, pp. 397-448, 1970.

[70] N. Nathanson and G. A. Cole, "Immunosuppression: a means to assess the role of the immune response in acute virus infections," Federation Proceedings, vol. 30, no. 6, pp. 1822-1830, 1971.

[71] E. Konishi, I. Kurane, P. W. Mason, B. L. Innis, and F. A. Ennis, "Japanese encephalitis virus-specific proliferative responses of human peripheral blood T lymphocytes," American Journal of Tropical Medicine and Hygiene, vol. 53, no. 3, pp. 278-283, 1995.

[72] H. Aihara, T. Takasaki, T. Matsutani, R. Suzuki, and I. Kurane, "Establishment and characterization of japanese encephalitis virus- specific, human CD4+ T-cell clones: flavivirus crossreactivity, protein recognition, and cytotoxic activity," Journal of Virology, vol. 72, no. 10, pp. 8032-8036, 1998.

[73] P. Kumar, P. Sulochana, G. Nirmala, R. Chandrashekar, M. Haridattatreya, and V. Satchidanandam, "Impaired T helper 1 function of nonstructural protein 3-specific T cells in japanese patients with encephalitis with neurological sequelae," The Journal of Infectious Diseases, vol. 189, no. 5, pp. 880-891, 2004.

[74] P. Kumar, P. Sulochana, G. Nirmala, M. Haridattatreya, and V. Satchidanandam, "Conserved amino acids 193-324 of nonstructural protein 3 are a dominant source of peptide determinants for CD4+ and CD8+ $\mathrm{T}$ cells in a healthy Japanese encephalitis virus-endemic cohort," Journal of General Virology, vol. 85, no. 5, pp. 1131-1143, 2004.

[75] S. K. Verma, N. Gupta, P. Pattnaik, J. Pradeep Babu, P. V. Lakshmana Rao, and S. Kumar, "Antibodies against refolded recombinant envelope protein (Domain III) of Japanese encephalitis virus inhibit the JEV infection to porcine stable kidney cells," Protein and Peptide Letters, vol. 16, no. 11, pp. 1334-1341, 2009.

[76] F. L. Jia and Z. X. Huang, "Cell-mediated immunity in mice infected with Japanese encephalitis virus. II. Passive transfer of immune spleen T cells for life protection in infected mice," Zhongguo Yi Xue Ke Xue Yuan Xue Bao, vol. 5, no. 1, pp. 68-69, 1983.

[77] V. J. Lad, A. K. Gupta, M. K. Goverdhan, V. L. Ayachit, J. J. Rodrigues, and L. V. Hungund, "Susceptibility of BL6 nude (congenitally athymic) mice to Japanese encephalitis virus by the peripheral route," Acta Virologica, vol. 37, no. 4, pp. 232-240, 1993.

[78] K. Miura, T. Onodera, A. Nishida, N. Goto, and Y. Fujisaki, “A single gene controls resistance to Japanese encephalitis virus in mice," Archives of Virology, vol. 112, no. 3-4, pp. 261-270, 1990.

[79] R. Mori, K. Kimoto, and K. Takeya, "The role of the thymus in antibody production and in resistance to Japanese encephalitis virus infection," Arch Gesamte Virusforsch, vol. 29, no. 1, pp. 3238, 1970.

[80] C. H. Pan, H. W. Chen, H. W. Huang, and M. H. Tao, "Protective mechanisms induced by a japanese encephalitis virus DNA vaccine: requirement for antibody but not CD8+ cytotoxic Tcell responses," Journal of Virology, vol. 75, no. 23, pp. 1145711463, 2001.

[81] J. An, D. S. Zhou, J. L. Zhang, H. Morida, J. L. Wang, and K. Yasui, "Dengue-specific CD8+ T cells have both protective and pathogenic roles in dengue virus infection," Immunology Letters, vol. 95, no. 2, pp. 167-174, 2004.

[82] Y.Zhang, N. Chirmule, G. P. Gao et al., "Acute cytokine response to systemic adenoviral vectors in mice is mediated by dendritic cells and macrophages," Molecular Therapy, vol. 3, no. 5, pp. 697-707, 2001.

[83] S. Cao, Y. Li, J. Ye et al., "Japanese Encephalitis virus wild strain infection suppresses dendritic cells maturation and function, and causes the expansion of regulatory T cells," Virology Journal, vol. 8, article 39, 2011.

[84] V. Saxena, A. Mathur, N. Krishnani, and T. N. Dhole, "Kinetics of cytokine profile during intraperitoneal inoculation of Japanese encephalitis virus in BALB/c mice model," Microbes and Infection, vol. 10, no. 10-11, pp. 1210-1217, 2008.

[85] V. Saxena, A. Mathur, N. Krishnani, and T. N. Dhole, "An insufficient anti-inflammatory cytokine response in mouse brain is associated with increased tissue pathology and viral load during Japanese encephalitis virus infection," Archives of Virology, vol. 153, no. 2, pp. 283-292, 2008.

[86] Y. Liu, N. King, A. Kesson, R. V. Blanden, and A. Mullbacher, "Flavivirus infection up-regulates the expression of class I and class II major histocompatibility antigens on and enhances $\mathrm{T}$ cell recognition of astrocytes in vitro," Journal of Neuroimmunology, vol. 21, no. 2-3, pp. 157-168, 1989.

[87] T. Kawai and S. Akira, "Innate immune recognition of viral infection," Nature Immunology, vol. 7, no. 2, pp. 131-137, 2006.

[88] S. Pestka, C. D. Krause, D. Sarkar, M. R. Walter, Y. Shi, and P. B. Fisher, "Interleukin-10 and related cytokines and receptors," Annual Review of Immunology, vol. 22, pp. 929-979, 2004.

[89] V. Swarup, J. Ghosh, R. Duseja, S. Ghosh, and A. Basu, "Japanese encephalitis virus infection decrease endogenous IL-10 production: correlation with microglial activation and neuronal death," Neuroscience Letters, vol. 420, no. 2, pp. 144-149, 2007.

[90] V. Swarup, J. Ghosh, S. Ghosh, A. Saxena, and A. Basu, "Antiviral and anti-inflammatory effects of rosmarinic acid in an experimental murine model of Japanese encephalitis," Antimicrobial Agents and Chemotherapy, vol. 51, no. 9, pp. 33673370, 2007.

[91] Y. Li, J. Ye, X. Yang et al., "Infection of mouse bone marrowderived dendritic cells by live attenuated Japanese encephalitis virus induces cells maturation and triggers T cells activation," Vaccine, vol. 29, no. 4, pp. 855-862, 2011.

[92] A. G. Aleyas, Y. W. Han, J. A. George et al., "Multifront assault on antigen presentation by Japanese encephalitis virus subverts CD8+ T cell responses," Journal of Immunology, vol. 185, no. 3, pp. 1429-1441, 2010.

[93] A. G. Aleyas, J. A. George, Y. W. Han et al., "Functional modulation of dendritic cells and macrophages by Japanese encephalitis virus through MyD88 adaptor molecule-dependent and independent pathways," Journal of Immunology, vol. 183, no. 4, pp. 2462-2474, 2009.

[94] Y. Wang, M. Lobigs, E. Lee, and A. Müllbacher, "Exocytosis and Fas mediated cytolytic mechanisms exert protection from West 
Nile virus induced encephalitis in mice," Immunology and Cell Biology, vol. 82, no. 2, pp. 170-173, 2004.

[95] T. Solomon, N. M. Dung, R. Kneen, M. Gainsborough, D. W. Vaughn, and V. T. Khanh, "Japanese encephalitis," Journal of Neurology Neurosurgery and Psychiatry, vol. 68, no. 4, pp. 405$415,2000$.

[96] A. Shrivastva, N. Tripathi, M. Parida, P. Dash, A. Jana, and P. Lakshmana Rao, "Comparison of a dipstick enzyme-linked immunosorbent assay with commercial assays for detection of Japanese encephalitis virus-specific IgM antibodies," Journal of Postgraduate Medicine, vol. 54, no. 3, pp. 181-185, 2008.

[97] V. Ravi, A. Desai, M. Balaji et al., "Development and evaluation of a rapid IgM capture ELISA (JEV-Chex) for the diagnosis of Japanese encephalitis," Journal of Clinical Virology, vol. 35, no. 4, pp. 429-434, 2006.

[98] M. J. Zhang, M. J. Wang, S. Z. Jiang, and W. Y. Ma, "Passive protection of mice, goats, and monkeys against Japanese encephalitis with monoclonal antibodies," Journal of Medical Virology, vol. 29, no. 2, pp. 133-138, 1989.

[99] J. Kimura Kuroda and K. Yasui, “Topographical analysis of antigenic determinants on envelope glycoprotein V3 (E) of Japanese encephalitis virus, using monoclonal antibodies," Journal of Virology, vol. 45, no. 1, pp. 124-132, 1983.

[100] R. T. Johnson, D. S. Burke, M. Elwell et al., "Japanese encephalitis: immunocytochemical studies of viral antigen and inflammatory cells in fatal cases," Annals of Neurology, vol. 18, no. 5, pp. 567-573, 1985.

[101] E. Konishi, S. Pincus, E. Paoletti, R. E. Shope, T. Burrage, and P. W. Mason, "Mice immunized with a subviral particle containing the Japanese encephalitis virus prM/M and $\mathrm{E}$ proteins are protected from lethal JEV infection," Virology, vol. 188, no. 2, pp. 714-720, 1992.

[102] C. W. Lin, K. T. Liu, H. D. Huang, and W. J. Chen, "Protective immunity of E. coli-synthesized NS1 protein of Japanese encephalitis virus," Biotechnology Letters, vol. 30, no. 2, pp. 205214, 2008.

[103] Y. L. Lin, L. K. Chen, C. L. Liao et al., "DNA immunization with Japanese encephalitis virus nonstructural protein NS1 elicits protective immunity in mice," Journal of Virology, vol. 72, no. 1, pp. 191-200, 1998.

[104] P. W. Mason, S. Pincus, M. J. Fournier, T. L. Mason, R. E. Shope, and E. Paoletti, "Japanese encephalitis virus-vaccinia recombinants produce particulate forms of the structural membrane proteins and induce high levels of protection against lethal JEV infection," Virology, vol. 180, no. 1, pp. 294-305, 1991.

[105] V. D. Krishna, M. Rangappa, and V. Satchidanandam, "Virusspecific cytolytic antibodies to nonstructural protein 1 of Japanese encephalitis virus effect reduction of virus output from infected cells," Journal of Virology, vol. 83, no. 10, pp. 4766-4777, 2009.

[106] A. P. Goncalvez, C. H. Chien, K. Tubthong et al., "Humanized monoclonal antibodies derived from chimpanzee fabs protect against Japanese encephalitis virus in vitro and in vivo," Journal of Virology, vol. 82, no. 14, pp. 7009-7021, 2008.

[107] E. Konishi, S. Pincus, E. Paoletti, W. W. Laegreid, R. E. Shope, and P. W. Mason, "A highly attenuated host range-restricted vaccinia virus strain, NYVAC, encoding the prM, E, and NS1 genes of Japanese encephalitis virus prevents JEV viremia in swine," Virology, vol. 190, no. 1, pp. 454-458, 1992.

[108] A. Yasuda, J. Kimura-Kuroda, M. Ogimoto et al., "Induction of protective immunity in animals vaccinated with recombinant vaccinia viruses that express PreM and E glycoproteins of Japanese encephalitis virus," Journal of Virology, vol. 64, no. 6, pp. 2788-2795, 1990.

[109] C. Ramakrishna, V. Ravi, A. Desai, D. K. Subbakrishna, S. K. Shankar, and A. Chandramuki, "T helper responses to Japanese encephalitis virus infection are dependent on the route of inoculation and the strain of mouse used," Journal of General Virology, vol. 84, no. 6, pp. 1559-1567, 2003.

[110] E. A. Gould and A. Buckley, "Antibody-dependent enhancement of yellow fever and Japanese encephalitis virus neurovirulence," Journal of General Virology, vol. 70, no. 6, pp. 1605-1608, 1989.

[111] E. A. Gould, A. Buckley, B. K. Groeger, P. A. Cane, and M. Doenhoff, "Immune enhancement of yellow fever virus neurovirulence for mice: studies of mechanisms involved," Journal of General Virology, vol. 68, no. 12, pp. 3105-3112, 1987.

[112] A. D. T. Barrett and E. A. Gould, "Antibody-mediated early death in vivo after infection with yellow fever virus," Journal of General Virology, vol. 67, no. 11, pp. 2539-2542, 1986.

[113] S. C. Kliks, A. Nisalak, W. E. Brandt, L. Wahl, and D. S. Burke, "Antibody-dependent enhancement of dengue virus growth in human monocytes as a risk factor for dengue hemorrhagic fever," American Journal of Tropical Medicine and Hygiene, vol. 40, no. 4, pp. 444-451, 1989.

[114] A. P. McCaffrey, L. Meuse, T. T. T. Pham, D. S. Conklin, G. J. Hannon, and M. A. Kay, "RNA interference in adult mice," Nature, vol. 418, no. 6893, pp. 38-39, 2002.

[115] O. Voinnet, "RNA silencing as a plant immune system against viruses," Trends in Genetics, vol. 17, no. 8, pp. 449-459, 2001.

[116] N. E. Yelina, E. I. Savenkov, A. G. Solovyev, S. Y. Morozov, and J. P. T. Valkonen, "Long-distance movement, virulence, and RNA silencing suppression controlled by a single protein in hordei- and potyviruses: complementary functions between virus families," Journal of Virology, vol. 76, no. 24, pp. 1298112991, 2002.

[117] C. D. Novina, M. F. Murray, D. M. Dykxhoorn et al., "siRNAdirect inhibition of HIV-1 infection," Nature Medicine, vol. 8, pp. 681-686, 2002.

[118] M. Kitabwalla and R. M. Ruprecht, "RNA interference-a new weapon against HIV and beyond," The New England Journal of Medicine, vol. 347, no. 17, pp. 1364-1367, 2002.

[119] M. A. Martínez, A. Gutiérrez, M. Armand-Ugón et al., "Suppression of chemokine receptor expression by RNA interference allows for inhibition of HIV-1 replication," AIDS, vol. 16, no. 18, pp. 2385-2390, 2002.

[120] A. F. Ochsenbein, D. D. Pinschewer, B. Odermatt, M. C. Carroll, H. Hengartner, and R. M. Zinkernagel, "Protective T cellindependent antiviral antibody responses are dependent on complement," Journal of Experimental Medicine, vol. 190, no. 8, pp. 1165-1174, 1999.

[121] J. E. Volanakis, "The role of complement in innate and adaptive immunity, Current Topics in Microbiology and Immunology, vol. 266, pp. 41-56, 2002.

[122] M. Kopf, B. Abel, A. Gallimore, M. Carroll, and M. F. Bachmann, "Complement component C3 promotes T-cell priming and lung migration to control acute influenza virus infection," Nature Medicine, vol. 8, no. 4, pp. 373-378, 2002.

[123] M. C. Carroll, "The complement system in regulation of adaptive immunity," Nature Immunology, vol. 5, no. 10, pp. 981986, 2004. 
[124] G. Lindahl, U. Sjöbring, and E. Johnsson, "Human complement regulators: a major target for pathogenic microorganisms," Current Opinion in Immunology, vol. 12, no. 1, pp. 44-51, 2000.

[125] H. J. Muller-Eberhard, "Molecular organization and function of the complement system," Annual Review of Biochemistry, vol. 57, pp. 321-347, 1988.

[126] H. W. Favoreal, G. R. Van de Walle, H. J. Nauwynck, and M. B. Pensaert, "Virus complement evasion strategies," Journal of General Virology, vol. 84, no. 1, pp. 1-15, 2003.

[127] A. Sahu, S. N. Isaacs, A. M. Soulika, and J. D. Lambris, "Interaction of vaccinia virus complement control protein with human complement proteins: factor I-mediated degradation of C3b to iC3b1 inactivates the alternative complement pathway," Journal of Immunology, vol. 160, no. 11, pp. 5596-5604, 1998.

[128] J. J. Schlesinger and S. Chapman, "Neutralizing F(ab')2 fragments of protective monoclonal antibodies to yellow fever virus (YF) envelope protein fail to protect mice against lethal YF encephalitis," Journal of General Virology, vol. 76, no. 1, pp. 217220, 1995.

[129] M. A. Brinton, H. Arnheiter, and O. Haller, "Interferon independence of genetically controlled resistance to flaviviruses," Infection and Immunity, vol. 36, no. 1, pp. 284-288, 1982.

[130] E. A. Henchal, L. S. Henchal, and J. J. Schlesinger, "Synergistic interactions of anti-NS1 monoclonal antibodies protect passively immunized mice from lethal challenge with dengue 2 virus," Journal of General Virology, vol. 69, no. 8, pp. 2101-2107, 1988.

[131] M. Saini and S. Vrati, "A Japanese encephalitis virus peptide present on Johnson grass mosaic virus-like particles induces virus-neutralizing antibodies and protects mice against lethal challenge," Journal of Virology, vol. 77, no. 6, pp. 3487-3494, 2003.

[132] B. M. Kaufman, P. L. Summers, D. R. Dubois et al., "Monoclonal antibodies for dengue virus prM glycoprotein protect mice against lethal dengue infection," American Journal of Tropical Medicine and Hygiene, vol. 41, no. 5, pp. 576-580, 1989.

[133] J. Kimura-Kuroda and K. Yasui, "Protection of mice against Japanese encephalitis virus by passive administration with monoclonal antibodies," Journal of Immunology, vol. 141, no. 10, pp. 3606-3610, 1988.

[134] P. W. Mason, "Maturation of Japanese encephalitis virus glycoproteins produced by infected mammalian and mosquito cells," Virology, vol. 169, no. 2, pp. 354-364, 1989.

[135] B. Falgout, M. Bray, J. J. Schlesinger, and C. J. Lai, "Immunization of mice with recombinant vaccinia virus expressing authentic dengue virus nonstructural protein NS1 protects against lethal dengue virus encephalitis," Journal of Virology, vol. 64, no. 9, pp. 4356-4363, 1990.

[136] J. R. Putnak and J. J. Schlesinger, "Protection of mice against yellow fever virus encephalitis by immunization with a vaccinia virus recombinant encoding the yellow fever virus nonstructural proteins, NS1, NS2a and NS2b," Journal of General Virology, vol. 71, no. 8, pp. 1697-1702, 1990.

[137] G. Colombage, R. Hall, M. Pavy, and M. Lobigs, "DNAbased and alphavirus-vectored immunisation with PrM and E proteins elicits long-lived and protective immunity against the flavivirus, Murray Valley encephalitis virus," Virology, vol. 250, no. 1, pp. 151-163, 1998.

[138] A. K. I. Falconar, "Identification of an epitope on the dengue virus membrane $(\mathrm{M})$ protein defined by cross-protective monoclonal antibodies: design of an improved epitope sequence based on common determinants present in both envelope (E and M) proteins," Archives of Virology, vol. 144, no. 12, pp. 23132330, 1999 .

[139] S. Pincus, P. W. Mason, E. Konishi et al., "Recombinant vaccinia virus producing the prM and E proteins of yellow fever virus protects mice from lethal yellow fever encephalitis," Virology, vol. 187, no. 1, pp. 290-297, 1992.

[140] S. Vázquez, M. G. Guzmán, G. Guillen et al., "Immune response to synthetic peptides of dengue prM protein," Vaccine, vol. 20, no. 13-14, pp. 1823-1830, 2002.

[141] H. Ni, N. J. Burns, G. J. J. Chang et al., "Comparison of nucleotide and deduced amino acid sequence of the 5 ' noncoding region and structural protein genes of the wild-type Japanese encephalitis virus strain SA14 and its attenuated vaccine derivatives," Journal of General Virology, vol. 75, no. 6, pp. 1505-1510, 1994.

[142] H. Ni, G. J. J. Chang, H. Xie, D. W. Trent, and A. D. T. Barrett, "Molecular basis of attenuation of neurovirulence of wild-type Japanese encephalitis virus strain SA14," Journal of General Virology, vol. 76, no. 2, pp. 409-413, 1995.

[143] T. C. Yang, S. L. Shiu, P. H. Chuang et al., "Japanese encephalitis virus NS2B-NS3 protease induces caspase 3 activation and mitochondria-mediated apoptosis in human medulloblastoma cells," Virus Research, vol. 143, no. 1, pp. 77-85, 2009.

[144] A. Kaczor and D. Matosiuk, "Structure-based virtual screening for novel inhibitors of Japanese encephalitis virus NS3 helicase/nucleoside triphosphatase," FEMS Immunology and Medical Microbiology, vol. 58, no. 1, pp. 91-101, 2010.

[145] M. S. Diamond, "Evasion of innate and adaptive immunity by flaviviruses," Immunology and Cell Biology, vol. 81, no. 3, pp. 196-206, 2003.

[146] J. J. Wang, C. L. Liao, C. I. Yang, Y. L. Lin, C. T. Chiou, and L. K. Chen, "Localizations of NS3 and E proteins in mouse brain infected with mutant strain of Japanese encephalitis virus," Archives of Virology, vol. 143, no. 12, pp. 2353-2369, 1998.

[147] W. J. Liu, P. L. Sedlak, N. Kondratieva, and A. A. Khromykh, "Complementation analysis of the flavivirus Kunjin NS3 and NS5 proteins defines the minimal regions essential for formation of a replication complex and shows a requirement of NS3 in cis for virus assembly," Journal of Virology, vol. 76, no. 21, pp. 10766-10775, 2002.

[148] C. T. Chiou, C. C. A. Hu, P. H. Chen, C. L. Liao, Y. L. Lin, and J. J. Wang, "Association of Japanese encephalitis virus NS3 protein with microtubules and tumour susceptibility gene 101 (TSG101) protein," Journal of General Virology, vol. 84, no. 10, pp. 27952805, 2003.

[149] K. B. Anderson, R. V. Gibbons, S. J. Thomas et al., "Preexisting Japanese encephalitis virus neutralizing antibodies and increased symptomatic dengue illness in a School-Based cohort in Thailand," PLoS Neglected Tropical Diseases, vol. 5, no. 10, Article ID e1311, 2011.

[150] H. Holzmann, F. X. Heinz, C. W. Mandl, F. Guirakhoo, and C. Kunz, "A single amino acid substitution in envelope protein $\mathrm{E}$ of tick-borne encephalitis virus leads to attenuation in the mouse model," Journal of Virology, vol. 64, no. 10, pp. 5156-5159, 1990.

[151] K. Desai, L. Coudeville, and F. Bailleux, "Modelling the longterm persistence of neutralizing antibody in adults after one dose of live attenuated Japanese encephalitis chimeric virus vaccine," Vaccine, vol. 30, no. 15, pp. 2510-2515, 2012.

[152] X. Y. Tang, H. X. Ma, C. Xu et al., "Surveillance of healthy people's Japanese encephalitis neutralizing antibody in some 
areas of Henan Province," Zhonghua Shi Yan He Lin Chuang Bing Du Xue Za Zhi, vol. 25, no. 6, pp. 401-404, 2011.

[153] K. Wang and V. Deubel, "Mice with different susceptibility to Japanese encephalitis virus infection show selective neutralizing antibody response and myeloid cell infectivity," PLOS ONE, vol. 6, no. 9, Article ID e24744, 2011.

[154] K. L. Mansfield, D. L. Horton, N. Johnson et al., "Flavivirusinduced antibody cross-reactivity," Journal of General Virology, vol. 92, no. 12, pp. 2821-2829, 2011.

[155] R. S. Gangwar, P. Shil, G. N. Sapkal, S. A. Khan, and M. M. Gore, "Induction of virus-specific neutralizing immune response against West Nile and Japanese encephalitis viruses by chimeric peptides representing T-helper and B-cell epitopes," Virus Research, vol. 163, no. 1, pp. 40-50, 2012.

[156] M. Ogawa, H. Okubo, Y. Tsuji, N. Yasui, and K. Someda, "Chronic progressive encephalitis occurring 13 years after Russian spring summer encephalitis," Journal of the Neurological Sciences, vol. 19, no. 3, pp. 363-373, 1973.

[157] S. Sharma, A. Mathur, V. Prakash, R. Kulshreshtha, R. Kumar, and U. C. Chaturvedi, "Japanese encephalitis virus latency in peripheral blood lymphocytes and recurrence of infection in children," Clinical and Experimental Immunology, vol. 85, no. 1, pp. 85-89, 1991.

[158] M. Liu, H. Chen, F. Luo et al., "Deletion of N-glycosylation sites of hepatitis $C$ virus envelope protein E1 enhances specific cellular and humoral immune responses," Vaccine, vol. 25, no. 36, pp. 6572-6580, 2007.

[159] C. E. Samuel, "Antiviral actions of interferon interferonregulated cellular proteins and their surprisingly selective antiviral activities," Virology, vol. 183, no. 1, pp. 1-11, 1991.

[160] T. P. Monath, R. G. McLean, C. B. Cropp, G. L. Parham, J. S. Lazuick, and C. H. Calisher, "Diagnosis of eastern equine encephalomyelitis by immunofluorescent staining of brain tissue," American Journal of Veterinary Research, vol. 42, no. 8, pp. 1418-1421, 1981.

[161] S. B. Halstead and S. J. Thomas, "New Japanese encephalitis vaccines: alternatives to production in mouse brain," Expert Review of Vaccines, vol. 10, no. 3, pp. 355-364, 2011.

[162] World Health Organization (WHO), "Position paper-Japanese encephalitis vaccines," Weekly Epidemiological Record, vol. 81, no. 34-35, pp. 331-340, 2006.

[163] World Health Organization (WHO), "Japanese encephalitis vaccines," Weekly Epidemiological Record, vol. 73, pp. 334-344, 1998.

[164] W.H.O 2005-2010. World Health Organization Department of Immunization, Vaccines and Biologicals, "Procedure for assessing the acceptability, in principle, of vaccines for purchase by United Nations agencies," http://whqlibdoc.who.int/hq/2006/ WHO_IVB_05.19_eng.pdf.

[165] WHO SEARO, “ Thailand 2007 EPI Fact Sheet, Data as reported in the 2007 WHO/UNICEF Joint Reporting Form on Immunization," 2008.

[166] C. Hatz, J. Werlein, M. Mutsch, M. R. Hufnagel, and R. H. Behrens, "Japanese encephalitis: defining risk incidence for travelers to endemic countries and vaccine prescribing from the UK and Switzerland," Journal of Travel Medicine, vol. 16, no. 3, pp. 200-203, 2009.

[167] S. B. Halstead and T. F. Tsai, "Japanese encephalitis vaccines," in Vaccines, S. A. Plotkin and W. A. Orenstein, Eds., Saunders, Philadelphia, Pa, USA, 4th edition, 2004.
[168] S. B. Halstead and J. Jacobson, "Japanese encephalitis," in The Flaviviruses: Detection, Diagnosis and Vaccine Development, T. Chambers and T. Monath, Eds., Elsevier, Academic Press, San Diego, Calif, USA, 2003.

[169] K. Dubischar-Kastner, S. Eder, V. Buerger et al., "Long-term immunity and immune response to a booster dose following vaccination with the inactivated Japanese encephalitis vaccine IXIARO, IC51," Vaccine, vol. 28, no. 32, pp. 5197-5202, 2010.

[170] E. Ohtaki, T. Matsuishi, Y. Hirano, and K. Maekawa, "Acute disseminated encephalomyelitis after treatment with Japanese B encephalitis vaccine (Nakayama-Yoken and Beijing strains)," Journal of Neurology Neurosurgery and Psychiatry, vol. 59, no. 3, pp. 316-317, 1995.

[171] J. Hombach, T. Solomon, I. Kurane, J. Jacobson, and D. Wood, "Report on a WHO consultation on immunological endpoints for evaluation of new Japanese encephalitis vaccines, WHO, Geneva, 2-3 September, 2004," Vaccine, vol. 23, no. 45, pp. 5205$5211,2005$.

[172] C. H. Hoke, A. Nisalak, N. Sangawhipa et al., "Protection against Japanese encephalitis by inactivated vaccines," The New England Journal of Medicine, vol. 319, no. 10, pp. 608-614, 1988.

[173] S. E. Yang, M. J. Pan, H. F. Tseng, and M. Y. Liau, "The efficacy of mouse-brain inactivated Nakayama strain Japanese encephalitis vaccine-results from 30 years experience in Taiwan," Vaccine, vol. 24, no. 14, pp. 2669-2673, 2006.

[174] D. R. Shlim and T. Solomon, "Japanese encephalitis vaccine for travelers: exploring the limits of risk," Clinical Infectious Diseases, vol. 35, no. 2, pp. 183-188, 2002.

[175] E. Tauber, H. Kollaritsch, M. Korinek et al., "Safety and immunogenicity of a Vero-cell-derived, inactivated Japanese encephalitis vaccine: a non-inferiority, phase III, randomised controlled trial," The Lancet, vol. 370, no. 9602, pp. 1847-1853, 2007.

[176] J. Torresi, K. McCarthy, E. Feroldi, and C. Méric, "Immunogenicity, safety and tolerability in adults of a new singledose, live-attenuated vaccine against Japanese encephalitis: randomised controlled phase 3 trials," Vaccine, vol. 28, no. 50, pp. 7993-8000, 2010.

[177] E. Konishi, N. Ajiro, C. Nukuzuma, P. W. Mason, and I. Kurane, "Comparison of protective efficacies of plasmid DNAs encoding Japanese encephalitis virus proteins that induce neutralizing antibody or cytotoxic T lymphocytes in mice," Vaccine, vol. 21, no. 25-26, pp. 3675-3683, 2003.

[178] J. Arroyo, F. Guirakhoo, S. Fenner, Z. X. Zhang, T. P. Monath, and T. J. Chambers, "Molecular basis for attenuation of neurovirulence of a yellow fever virus/Japanese encephalitis virus chimera vaccine (ChimeriVax-JE)," Journal of Virology, vol. 75, no. 2, pp. 934-942, 2001.

[179] P. E. Nasveld, A. Ebringer, N. Elmes et al., "Long term immunity to live attenuated Japanese encephalitis chimeric virus vaccine: randomized, double-blind, 5-year phase II study in healthy adults," Human Vaccines, vol. 6, no. 12, pp. 1038-1046, 2010.

[180] D. W. C. Beasley, C. T. Davis, J. Estrada-Franco et al., "Genome sequence and attenuating mutations in Nile virus isolate from Mexico," Emerging Infectious Diseases, vol. 10, no. 12, pp. 22212224, 2004.

[181] P. Liu, H. Lu, S. Li et al., "Genomic and antigenic characterization of the newly emerging Chinese duck egg-drop syndrome flavivirus: genomic comparison with Tembusu and Sitiawan viruses," The Journal of General Virology, vol. 93, part 10, pp. 2158-2170, 2012. 
[182] D. M. Knipe and P. M. Howley, Eds., Fields Virology, vol. 2 of Flaviviridae, the Viruses and Their Replication, chapter, Lippincott-Raven, Philadelphia, Pa, USA, 5th edition, 2007.

[183] E. Tauber, H. Kollaritsch, F. Von Sonnenburg et al., "Randomized, double-blind, placebo-controlled phase 3 trial of the safety and tolerability of IC51, an inactivated Japanese encephalitis vaccine," The Journal of Infectious Diseases, vol. 198, no. 4, pp. 493-499, 2008.

[184] U.S. Public Health Service, Centers for Disease Control, National Institutes of Health. Biosafety in Microbiological and Biomedical Laboratories, Washington, DC, USA, U. S. Public Health Service, 1988.

[185] S. Pasteur, http://www.sanofipasteur.com/sanofi-pasteur2/ front/index.jsp?siteCodepSP_CORP\&codeRubriquep34.

[186] H. Kollaritsch, M. Paulke-Korinek, and K. Dubischar-Kastner, "IC51 Japanese encephalitis vaccine," Expert Opinion on Biological Therapy, vol. 9, no. 7, pp. 921-931, 2009.

[187] B. Guy, F. Guirakhoo, V. Barban, S. Higgs, T. P. Monath, and J. Lang, "Preclinical and clinical development of YFV 17Dbased chimeric vaccines against dengue, West Nile and Japanese encephalitis viruses," Vaccine, vol. 28, no. 3, pp. 632-649, 2010.

[188] H. Ni, N. J. Burns, G. J. J. Chang et al., "Comparison of nucleotide and deduced amino acid sequence of the 5' noncoding region and structural protein genes of the wild-type Japanese encephalitis virus strain SA14 and its attenuated vaccine derivatives," Journal of General Virology, vol. 75, no. 6, pp. 1505-1510, 1994.

[189] T. P. Monath, K. McCarthy, P. Bedford et al., "Clinical proof of principle for ChimeriVaxU: recombinant live, attenuated vaccines against flavivirus infections," Vaccine, vol. 20, no. 7-8, pp. 1004-1018, 2002.

[190] B. J. Montagnon, B. Fanget, and A. J. Nicolas, "The large-scale cultivation of VERO cells in micro-carrier culture for virus vaccine production. Preliminary results for killed poliovirus vaccine," Developments in Biological Standardization, vol. 47, pp. 55-64, 1980.

[191] E. Schuller, B. Jilma, V. Voicu et al., "Long-term immunogenicity of the new Vero cell-derived, inactivated Japanese encephalitis virus vaccine IC51. Six and 12 month results of a multicenter follow-up phase 3 study," Vaccine, vol. 26, no. 34 , pp. 4382-4386, 2008.

[192] E. Schuller, C. S. Klade, G. Wölfl, A. Kaltenböck, S. Dewasthaly, and E. Tauber, "Comparison of a single, high-dose vaccination regimen to the standard regimen for the investigational Japanese encephalitis vaccine, IC51: a randomized, observerblind, controlled Phase 3 study," Vaccine, vol. 27, no. 15, pp. 21882193, 2009.

[193] Centers for Disease Control and Prevention, "ACIP provisional recommendations," http://www.cdc.gov/vaccines/recs/provisional/\#acip.

[194] Intercell, "Japanese encephalitis vaccine," http://www.intercell .com/main/forvaccperts/products/japanese-encephalitis-vaccine/.

[195] S. Eder, K. Dubischar-Kastner, C. Firbas et al., "Long term immunity following a booster dose of the inactivated Japanese Encephalitis vaccine IXIARO, IC51," Vaccine, vol. 29, no. 14, pp. 2607-2612, 2011.

[196] A. Kaltenböck, K. Dubischar-Kastner, G. Eder et al., "Safety and immunogenicity of concomitant vaccination with the cell-culture based Japanese Encephalitis vaccine IC51 and the hepatitis A vaccine HAVRIX1440 in healthy subjects: a singleblind, randomized, controlled Phase 3 study," Vaccine, vol. 27, no. 33, pp. 4483-4489, 2009.

[197] K. H. Eckels, Y. Yong-Xin, D. R. Dubois, N. J. Marchette, D. W. Trent, and A. J. Johnson, "Japanese encephalitis virus liveattenuated vaccine, Chinese strain SA14-14-2; adaptation to primary canine kidney cell cultures and preparation of a vaccine for human use," Vaccine, vol. 6, no. 6, pp. 513-518, 1988.

[198] S. Hennessy, L. Zhengle, T. F. Tsai et al., "Effectiveness of liveattenuated Japanese encephalitis vaccine (SA14-14-2): a casecontrol study," The Lancet, vol. 347, no. 9015, pp. 1583-1586, 1996.

[199] P. E. Nasveld, A. Ebringer, N. Elmes et al., "Long term immunity to live attenuated Japanese encephalitis chimeric virus vaccine: randomized, double-blind, 5-year phase II study in healthy adults," Human Vaccines, vol. 6, no. 12, pp. 1038-1046, 2010.

[200] Y. Y. Xin, Z. G. Ming, G. Y. Peng, A. Jian, and L. H. Min, "Safety of a live-attenuated Japanese encephalitis virus vaccine (SA1414-2) for children," American Journal of Tropical Medicine and Hygiene, vol. 39, no. 2, pp. 214-217, 1988.

[201] D. W. C. Beasley, P. Lewthwaite, and T. Solomon, "Current use and development of vaccines for Japanese encephalitis," Expert Opinion on Biological Therapy, vol. 8, no. 1, pp. 95-106, 2008.

[202] K. Chokephaibulkit, C. Sirivichayakul, U. Thisyakorn et al., "Safety and immunogenicity of a single administration of liveattenuated japanese encephalitis vaccine in previously primed 2- to 5-year-olds and naive 12- to 24-month-olds: multicenter randomized controlled trial," Pediatric Infectious Disease Journal, vol. 29, no. 12, pp. 1111-1117, 2010.

[203] H. Ohrr, J. B. Tandan, Y. M. Sohn, S. H. Shin, D. P. Pradhan, and S. B. Halstead, "Effect of single dose of SA 14-14-2 vaccine 1 year after immunisation in Nepalese children with Japanese encephalitis: a case-control study," The Lancet, vol. 366, no. 9494, pp. 1375-1378, 2005.

[204] J. B. Tandan, H. Ohrr, Y. M. Sohn et al., "Single dose of SA 14-14-2 vaccine provides long-term protection against Japanese encephalitis: a case-control study in Nepalese children 5 years after immunization," Vaccine, vol. 25, no. 27, pp. 5041-5045, 2007.

[205] M. B. Bista, M. K. Banerjee, S. H. Shin et al., "Efficacy of singledose SA 14-14-2 vaccine against Japanese encephalitis: a case control study," The Lancet, vol. 358, no. 9284, pp. 791-795, 2001.

[206] S. Nimmannitya, S. Hutamai, S. Kalayanarooj, and S. Rojanasuphot, "A field study on Nakayama and Beijing strains of Japanese encephalitis vaccines," The Southeast Asian Journal of Tropical Medicine and Public Health, vol. 26, no. 4, pp. 689-693, 1995.

[207] N. Nitatpattana, A. Dubot-Pérès, M. Ar Gouilh et al., "Change in Japanese encephalitis virus distribution, Thailand," Emerging Infectious Diseases, vol. 14, no. 11, pp. 1762-1765, 2008.

[208] E. Konishi, M. Yamaoka, K. S. Khin-Sane-Win, I. Kurane, and P. W. Mason, "Induction of protective immunity against japanese encephalitis in mice by immunization with a plasmid encoding Japanese encephalitis virus premembrane and envelope genes," Journal of Virology, vol. 72, no. 6, pp. 4925-4930, 1998.

[209] W. Swaddiwuthipong, B. G. Weniger, S. Wattanasri, and M. J. Warrell, "A high rate of neurological complications following Semple anti-rabies vaccine," Transactions of the Royal Society of Tropical Medicine and Hygiene, vol. 82, no. 3, pp. 472-475, 1988.

[210] R. Kaur, G. Sachdeva, and S. Vrati, "Plasmid DNA immunization against Japanese encephalitis virus: immunogenicity of membrane-anchored and secretory envelope protein," The Journal of Infectious Diseases, vol. 185, no. 1, pp. 1-12, 2002. 
[211] C. Ramakrishna, A. Desai, S. K. Shankar, A. Chandramuki, and V. Ravi, "Oral immunisation of mice with live Japanese encephalitis virus induces a protective immune response," Vaccine, vol. 17, no. 23-24, pp. 3102-3108, 1999.

[212] A. S. Kolaskar and U. Kulkarni-Kale, "Prediction of threedimensional structure and mapping of conformational epitopes of envelope glycoprotein of Japanese encephalitis virus," Virology, vol. 261, no. 1, pp. 31-42, 1999.

[213] Patent (patent no. 7,425,335). Chimeric T helper-B cell peptide vaccine for Japanese encephalitis virus, Gore; M. M. (Pune, IN), Kolaskar; Ashok (Pune, IN), Dewasthaly; S. S. (Pune, IN), Kulkarani-Kale; Urmila D. (Pune, IN), Sawant; Sangeeta (Pune, IN), 2008.

[214] C. R. Robinson and R. T. Sauer, "Optimizing the stability of single-chain proteins by linker length and composition mutagenesis," Proceedings of the National Academy of Sciences of the United States of America, vol. 95, no. 11, pp. 5929-5934, 1998.

[215] M. H. V. Van Regenmortel, "Molecular design versus empirical discovery in peptide-based vaccines. Coming to terms with fuzzy recognition sites and ill-defined structure-function relationships in immunology," Vaccine, vol. 18, no. 3-4, pp. 216-221, 1999.

[216] M. Kuwahara and E. Konishi, "Evaluation of extracellular subviral particles of dengue virus type 2 and Japanese encephalitis virus produced by Spodoptera frugiperda cells for use as vaccine and diagnostic antigens," Clinical and Vaccine Immunology, vol. 17, no. 10, pp. 1560-1566, 2010.

[217] N. K. Tripathi, J. Shukla, K. C. Biswal, and P. V. Lakshmana Rao, "Development of a simple fed-batch process for the high-yield production of recombinant Japanese encephalitis virus protein," Applied Microbiology and Biotechnology, vol. 86, no. 6, pp. 17951803, 2010.

[218] M. B. Appaiahgari and S. Vrati, "DNAzyme-mediated inhibition of Japanese encephalitis virus replication in mouse brain," Molecular Therapy, vol. 15, no. 9, pp. 1593-1599, 2007.

[219] S. I. Yun, S. Y. Kim, C. M. Rice, and Y. M. Lee, "Development and application of a reverse genetics system for Japanese encephalitis virus," Journal of Virology, vol. 77, no. 11, pp. 64506465, 2003.

[220] Y. L. Lin, Y. L. Huang, S. H. Ma et al., "Inhibition of Japanese encephalitis virus infection by nitric oxide: antiviral effect of nitric oxide on RNA virus replication," Journal of Virology, vol. 71, no. 7, pp. 5227-5235, 1997. 

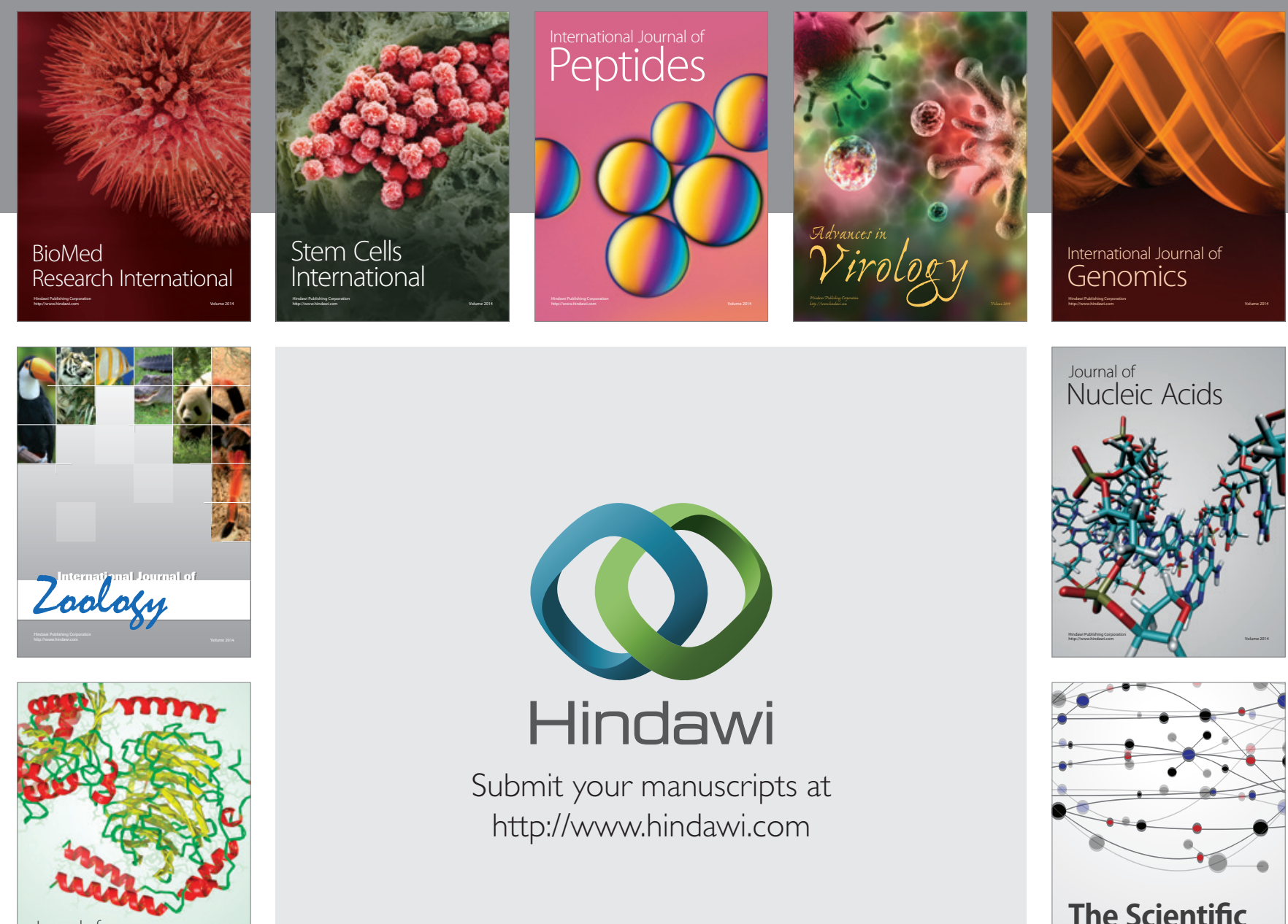

Submit your manuscripts at

http://www.hindawi.com

Journal of
Signal Transduction
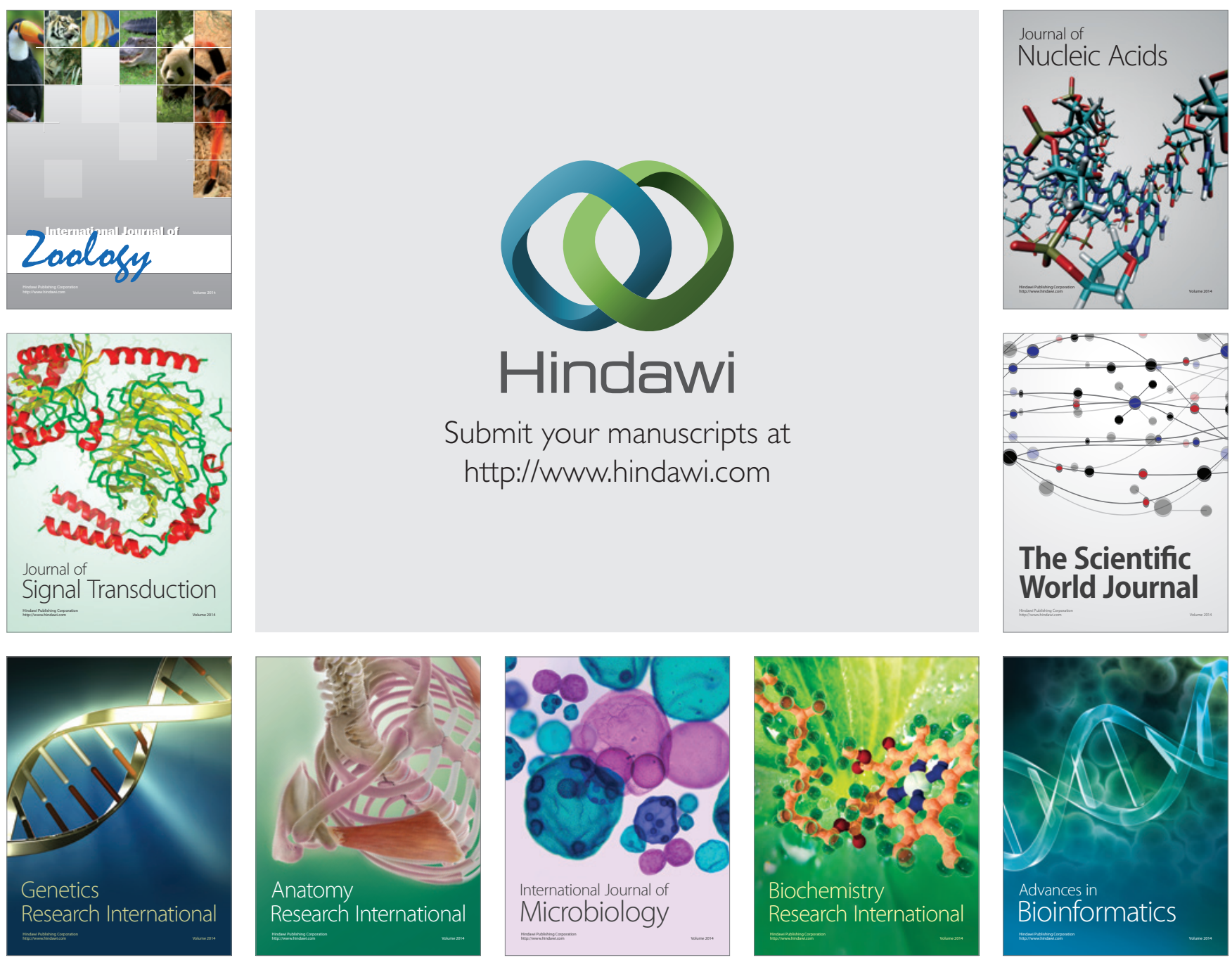

The Scientific World Journal
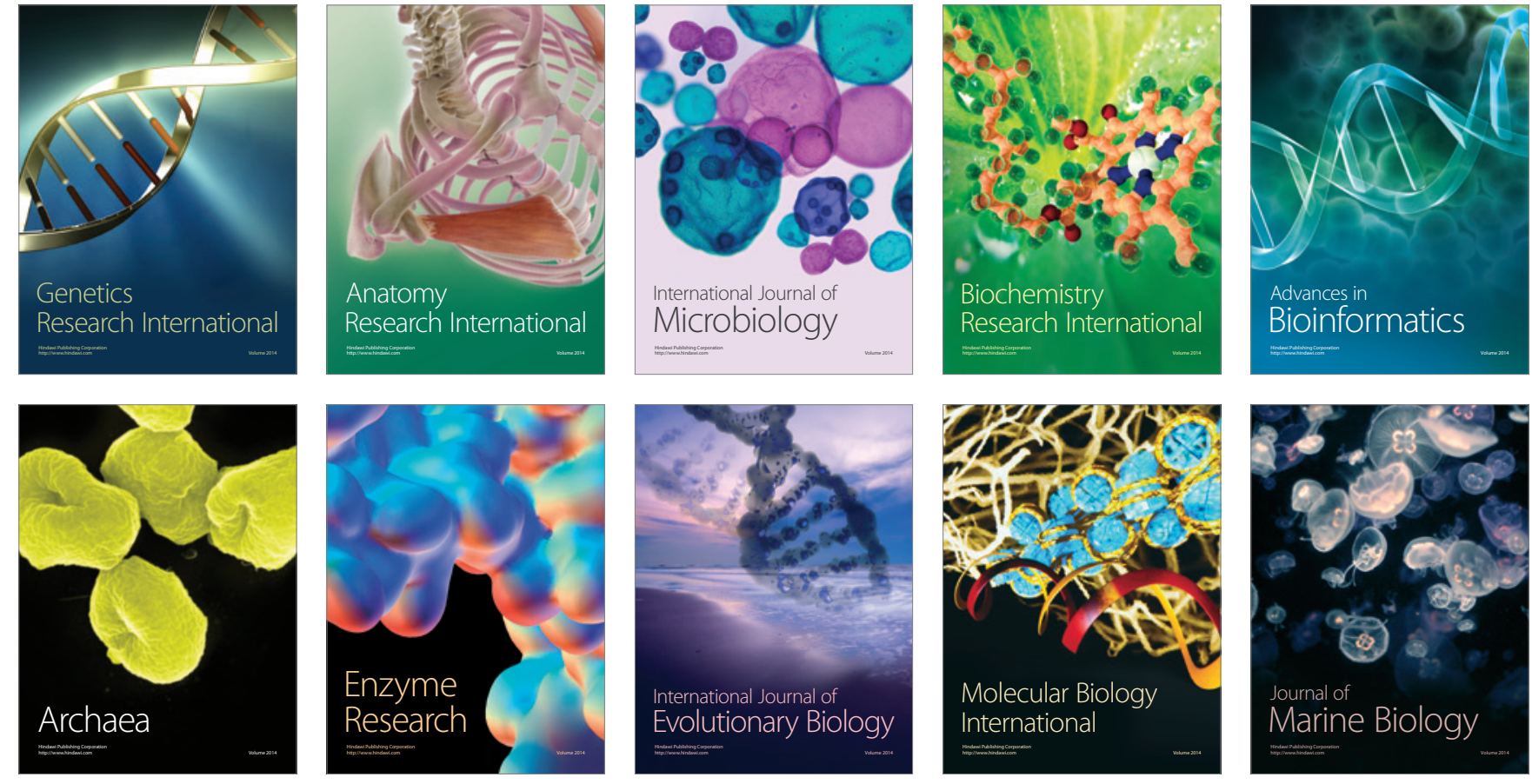